\title{
Relative Wealth Concerns, Executive Compensation, and Systemic Risk-Taking
}

Liu, Qi, and Bo Sun

Please cite paper as:

Liu, Qi, and Bo Sun (2016). Relative Wealth Concerns,

Executive Compensation, and Systemic Risk-Taking.

International Finance Discussion Papers 1164.

http://dx.doi.org/10.17016/IFDP.2016.1164

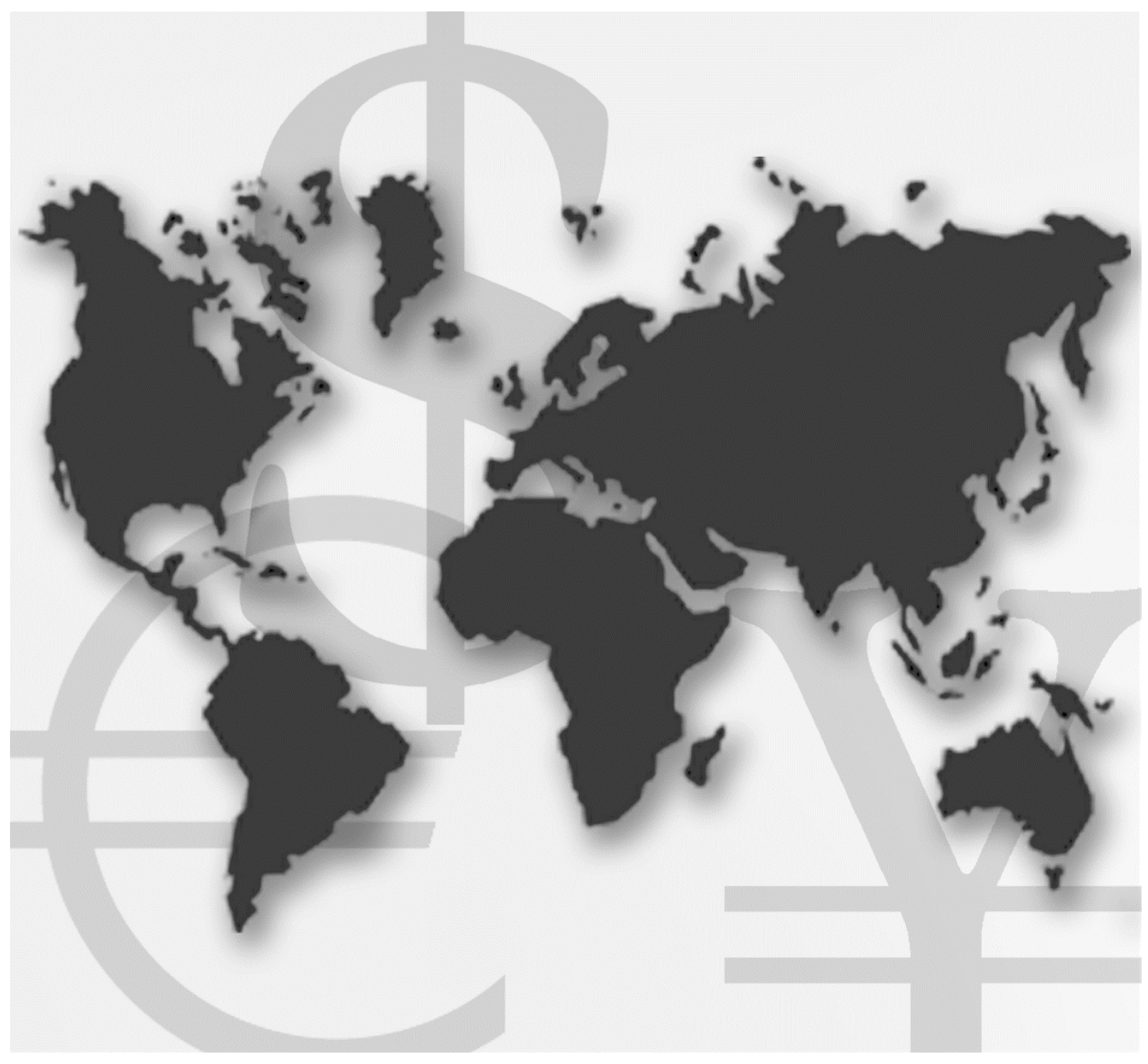

\section{International Finance Discussion Papers}

Board of Governors of the Federal Reserve System

Number 1164

May 2016 
Board of Governors of the Federal Reserve System

International Finance Discussion Papers

Number 1164

May 2016

\title{
Relative Wealth Concerns, Executive Compensation, and Systemic Risk-Taking
}

\author{
Qi Liu and Bo Sun
}

NOTE: International Finance Discussion Papers are preliminary materials circulated to stimulate discussion and critical comment. References to International Finance Discussion Papers (other than an acknowledgment that the writer has had access to unpublished material) should be cleared with the author or authors. Recent IFDPs are available on the Web at www.federalreserve.gov/pubs/ifdp/. This paper can be downloaded without charge from the Social Science Research Network electronic library at www.ssrn.com. 


\title{
Relative Wealth Concerns, Executive Compensation, and Systemic Risk-Taking ${ }^{1}$
}

\author{
Qi Liu \\ Bo Sun \\ Peking University \\ Federal Reserve Board
}

May, 2016

\footnotetext{
${ }^{1}$ We thank seminar participants at Peking University, SAIF, University of Delaware, University of Hong Kong, and Wharton School of Business for their helpful comments. The views expressed herein are the authors' and do not necessarily reflect the opinions of the Board of Governors of the Federal Reserve System.
} 


\title{
Relative Wealth Concerns, Executive Compensation, and Systemic Risk Taking
}

\begin{abstract}
Given the recent empirical evidence on peer effects in CEO compensation, this paper theoretically examines how relative wealth concerns, in which a manager's satisfaction with his own compensation depends on the compensation of other managers, affect the equilibrium contracting strategy and managerial risk-taking. We find that such externalities can generate pay-for-luck as an efficient compensation vehicle in equilibrium. In expectation of pay-for-luck in other firms, tying managerial pay to luck provides insurance to managers against a compensation shortfall relative to executive peers during market fluctuations. When all firms pay for luck, we show that an effort-inducing mechanism exists: managers have additional incentives to exert effort in utilizing investment opportunities, which helps them keep up with their peers during industry movements. In addition, we show that compensation arrangements involving pay-for-luck that are efficient from the shareholders' perspective can nonetheless exacerbate aggregate fluctuations in the real economy by incentivizing excessive systemic risk-taking, especially in periods of heightened risk.
\end{abstract}

Keywords: Relative wealth concerns, Managerial compensation, Pay-for-luck, Excessive risk-taking JEL Classifications: D822, D86. 


\section{Introduction}

It has long been argued that relative wealth effects, in which a person's satisfaction with their own wealth depends on the wealth of others, are a key component of utility (Veblen (1899), Frank (1985), and Galí (1994)). Relative wealth concerns are prevalent in the overall population, and they are especially common among successful experts and high-net-worth individuals. ${ }^{1}$ In particular, corproate executives enjoy lavish incomes and have frequent interactions within a social circle: most CEOs interact with peer CEOs by attending various social events and sharing membership in exclusive golf and country clubs, which inevitably invites comparisons and generates social ranks among CEOs based on various indicators of wealth. However, the academic literature that studies how to align the incentives of managers with those of shareholders largely ignores this trait. Since relative wealth concerns directly influence decision-making, it is logical to study the effects that relative considerations have on managerial behavior and firm value. How do relative wealth concerns affect managers' effort and investment decisions? How do compensation contracts optimally adjust for these effects? Can firms ever benefit from managerial relative wealth concerns?

We develop a stylized contracting model that enables us to answer these questions. In our model, a continuum of risk-neutral firms hire risk-averse managers with relative wealth concerns. In particular, we adopt a preference specification in which managers' marginal utility of compensation depends not only on their own compensation, but also on how their compensation compares with that of others. We analyze this contracting problem first in a setting where managerial relative concerns are confined within the community of executives, and then in a generalized setting that allows for relative considerations to extend beyond the exclusive circle of managers.

One key result of our model is that with managerial relative wealth concerns, tying CEO pay to observable industry events can emerge as an equilibrium compensation strategy. Empirical observations that managers are paid for exogenous and contractible shocks to performance that is, the pay-for-luck phenomenon documented by Bertrand and Mullainathan (2001) — have received considerable academic attention and shareholder scrutiny. Standard contracting models

\footnotetext{
${ }^{1}$ Veblen (1899) argues that the possession of wealth is the basis of reputability and of social standing, and the amount of consumption necessary to maintain one's social standing, as an important component of utility, increases over the course of wealth accumulation. Frank (1985) highlights the importance of relative wealth in determining social status.
} 
suggest that rewarding executives for observable changes in firm performance that are beyond the executives' control does not provide incentives and only makes the contract riskier (Holmstrom (1979)). Managerial power has been proposed as an alternative paradigm, interpreting pay-for-luck as suggestive of corporate governance failures. ${ }^{2}$ We show that when other firms are expected to pay their managers for luck, a manager with relative wealth concerns worries about falling behind his peers during market fluctuations if his contract does not give him as much exposure to the market component as others'. The insurance provision by pay-for-luck against a relative compensation shortfall delivers an equilibrium in which all firms pay for luck.

We also show that pay-for-luck can have an effort-inducing effect in equilibrium. When managers are sensitive to the wealth of others, the market component in other managers' pay provides effort incentives for an individual manager, because exerting effort in undertaking projects with payoffs that fluctuate with the market helps him keep up with peers. In the pay-for-luck equilibrium, this effort-inducing mechanism delivers higher shareholder payoff beyond that in the no-pay-for-luck equilibrium. Our results suggest that relative wealth concerns on the part of managers may enhance firms' ability to discipline managers, generating the use of pay-for-luck that is value-maximizing in a setting with moral hazard. Shareholders can actually benefit from managers' desire to catch up with executive peers and can improve firm value through efficient contracting.

By the same token, our model indicates that the interaction of managerial relative concerns and pay structure generates additional incentives to take risk, uncovering an overlooked relation between the use of pay-for-luck and corporate risk-taking. Because exposing firm value to aggregate fluctuations effectively helps managers maintain their relative income position in all states of the world, managers with pay-for-luck take risk more aggressively, especially in periods of increased aggregate risk. Standard models imply that firms take less risk to shy away from heightened aggregate fluctuations. Our model thus presents a countervailing force to this conventional argument and shows that pay-for-luck, though locally efficient within the firm due to managerial relative concerns, can nonetheless exacerbate fluctuations in the real economy in periods of intensified aggregate risk.

In order to study the implications of relative wealth concerns for systemic risk-taking, we extend our model to allow managers to choose the firm's exposure to market risk above and beyond what

\footnotetext{
${ }^{2}$ See, for example, Bertrand and Mullainathan (2001) and Bebchuk and Fried (2004).
} 
is associated with their effort decision. In this context, as correlating one's risk exposure with other firms' helps prevent compensation downfalls relative to one's peers, compensation contracts that optimally adjust for managerial relative concerns would actually allow for increased systemic risk-taking. Hence, managerial relative considerations lead to a trade-off between the build-up of systemic risk and the creation of productive effort from a social welfare perspective.

To capture relative considerations in a global sense, we allow managerial relative concerns to extend beyond an exclusive circle of managers, and show that there exists a unique equilibrium in which all firms tie their managers' compensation to market movements, as long as the degree of relative wealth concerns is not too small. We also generalize our specification of relative concerns in a variety of ways to examine the robustness of our theoretical results. For example, we allow managers to care about each and every other manager differently, possibly depending on the peer's proximity, similarity in background, or position in the pay distribution; care about only a selected subset of managers such as those better-paid ones; or care about some leading managers whose contracts affect others'. The results in those generalized versions confirm our results and also demonstrate that a slight degree of relative considerations can deliver pay-for-luck as an equilibrium compensation strategy.

Our paper is motivated by a number of recent empirical studies that suggest that peers are a crucial determinant of executive pay. Bouwman (2013) finds that CEO pay is strongly correlated with that of geographically close CEOs and presents evidence that the pattern is likely driven by managerial relative status concerns. Shue (2013) documents the phenomenon of "pay for friend's luck" - pay responds to lucky industry-level shocks to the compensation of peers in distant industries. She also demonstrates the importance of contemporaneous social interactions by showing that peer similarities in compensation are more than twice as large in the year immediately following staggered alumni reunions. Bereskin and Cicero (2013) show that pay increases in a subset of firms in response to a governance shock affected compensation in other firms in the economy. Ang, Nagel, and Yang (2013) find that CEO compensation contains a component that is positively linked to social pressures due to interactions with other CEOs. Motivated by these empirical findings, we theoretically examine how managerial relative considerations affect the design of executive pay. ${ }^{3}$

\footnotetext{
${ }^{3}$ Previous studies on the effect of "social comparison" on executive pay are mainly concerned with the directors' network; see, for example, Larcker et al. (2005), Kovacevic (2005), Barnea and Guedj (2006), and Hwang and Kim
} 
It has long been puzzling that managers are rewarded for changes in firm performance that are beyond their control and that can be distinguished from their performance. To rationalize such a compensation practice, Hoffmann and Pfeil (2010) and Noe and Rebello (2012) show that pay-forluck can arise in a dynamic model if luck shocks are informative of future profitability. Gopalan et al. (2010) and Feriozzi (2011) propose alternative hypotheses based on strategic flexibility and implicit incentives created by the likelihood of bankruptcy, respectively. The models of Himmelberg and Hubbard (2000), Oyer (2004), and Chaigneau and Sahuguet (2012) show that pay-for-luck can be driven by changes in CEOs' reservation wages, as determined in a competitive labor market. In a calibration, Dittmann et al. (2013) find that pay-for-luck is not very costly to firms. None of these papers, however, explicitly examine the role of relative wealth concerns, which is at the heart of our analysis.

The theoretical literature on relative wealth concerns is predominantly focused on the implications for financial markets (e.g., Abel (1990), Constantinide (1990), Galí (1994), Campbell and Cochrane (1999), and DeMarzo et al. (2008)). We differ from this literature in that we examine the consequences relative wealth concerns have on corporate policies. A contemporaneous paper by DeMarzo and Kaniel (2015) shows that relative considerations can cause an inadequate use of relative performance evaluation. While they analyze the welfare efficiency in various compensation settings, we focus on the implications for managerial risk-taking behavior, especially systemic risk. ${ }^{4}$ The closest paper to ours is Ozdenoren and Yuan (2015), which shows that with multiplicative effort, contractual externalities from relative performance evaluation can generate excessive systemic risk-taking. Their results are based on the assumptions that the principals are risk-averse, and the signal about the industry productivity shock (i.e., the aggregate shock) is noisy. In contrast, the principal in our model is risk-neutral, and the aggregate shock is assumed to be perfectly filtered out; incentives for excessive systemic risk-taking arise in our model are purely drive by managerial relative concerns. ${ }^{5}$

(2009).

${ }^{4}$ Also different from their use of average output of a discrete number of agents as the benchmark in relative evaluation, we allow the principal to perfectly filter out the component of firm value caused by aggregate shocks and to choose whether to include that in compensation. Our specification clearly distinguishes the luck component in pay and ensures that it does not contain any idiosyncratic movements.

${ }^{5}$ Our paper also contributes to the vast literature on the role of pay packages in firms' risk-taking by demonstrating a plausible relation between pay-for-luck and managerial risk-taking that has not been previously analyzed. Although the role of compensation strategy in firms' risk-taking has been extensively studied, a consensus on this subject has 
The rest of the paper is organized as follows. Section 2 describes the baseline model where managers are concerned about peer managers' pay. Section 3 analyzes efficient contracting in equilibrium and the implied risk-taking behavior. Section 4 generalizes the specification of managerial relative concerns to allow managers to have relative considerations beyond the community of corporate executives.. Section 5 discusses the model's empirical implications, and Section 6 concludes. The appendix contains the proofs and details on the model robustness to variants of relative concerns specifications.

\section{Model}

There is a continuum of firms indexed by $i \in[0,1]$, each owned by risk-neutral investors and operated by a risk-averse manager. For a representative firm $i$, we consider a single-period contracting model with time $t=0,1,2$. At $t=0$, the manager is offered a contract. At $t=1$, the manager exerts effort, denoted by $a_{i}$, which is unobservable to shareholders. At $t=2$, firm value is realized, and compensation is paid to the manager. We assume away heterogeneity in firms and managers; thus, we do not study efficient matching in managerial labor markets. ${ }^{6}$

\subsection{Preferences}

We assume that the manager at firm $i$ has preferences of the form $\mathbb{E}\left[u\left(w_{i}, \tilde{w}, a_{i}\right)\right]$, where $w_{i}$ denotes his compensation, $\tilde{w}$ characterizes executive peers' pay, and $a_{i}$ represents the manager's choice of effort. Specifically, we adopt a preference specification similar to that in Galí (1994) and García and Strobl (2011), and assume that the utility of the manager at firm $i$ is given by:

$$
u\left(w_{i}, \tilde{w}, a_{i}\right)=-\exp \left[-\lambda\left(w_{i}-\tilde{w}-\psi\left(a_{i}\right)\right)\right]
$$

where $\psi\left(a_{i}\right)=\frac{1}{2} a_{i}^{2}$ represents the cost of exerting effort to the manager. The one-step departure from the standard utility is that in our specification, it is relative pay, instead of absolute pay, that

not been reached. For example, Fahlenbrach and Stulz (2011) present evidence that bank CEOs lost a significant portion of their pay and argue that pay packages were not the likely cause of risk-taking. Bebchuk et al. (2010) show that prior to the crisis, executives had been granted compensation that was in great excess of what they lost during the crisis. Cheng et al. (2014) also present evidence that compensation payouts are tied to risk-taking incentives.

${ }^{6}$ Gabaix and Landier (2008) and Edmans and Gabaix (2011) present competitive assignment models of managerial labor markets. Archaya et al. (2013) study compensation efficiency when firms compete for scarce managerial talent. 
determines the manager's utility.

A manager with relative considerations may care not only about the level of other managers' pay but also about the structure of others' pay, which determines how much the manager's pay may be behind others in each possible state. To capture both the level and the structure of executive peers' pay, we assume that $\tilde{w}$ takes the following form:

$$
\tilde{w}=h_{l} \int_{0}^{1} E\left[w_{k}\right] d k+h_{s} \int_{0}^{1}\left(w_{k}-E\left[w_{k}\right]\right) d k
$$

where the parameters $h_{l}$ and $h_{s}$ reflect the extent of the compensation externality, i.e., how much manager $i$ cares about other managers' pay: $h_{l} \geq 0$ measures concerns regarding the absolute level of peers' pay, i.e., the average compensation of other managers across states; $h_{s} \geq 0$ measures concerns about the structure of peers' pay, i.e., the average compensation of other managers in each state. $E\left[w_{k}\right]$ is the expected pay of manager $k(\in[0,1])$ across states.

This functional form in (1) captures the notion that managers care about the compensation of other managers in a parsimonious way. We note that this utility function satisfies the usual conditions with respect to a manager's own compensation $w_{i}$ : it is increasing and concave in $w_{i}$, and the coefficient of absolute risk aversion is $-u_{11} / u_{1}=\lambda$. This utility specification also satisfies $u_{12} / u_{1}=\lambda$, which implies that an increase in the average managerial compensation in a state (or across states) raises the marginal utility of compensation when $h_{s}$ (or $h_{l}$ ) is positive, as the manager tries to catch up his peers. Our specification is consistent with the findings in Miglietta (2014), which shows in a laboratory experiment that individuals' utility increases in their wealth relative to their peers, and individuals are risk averse in their relative wealth.

We want to emphasize that our contribution is to study the effects of relative considerations on compensation design, and the particular interpretation of the utility function introduced above is not crucial. We note that managers we consider here care about the compensation of others in the community of executives. We subsequently extend our analysis to study relative wealth concerns that are global, in the sense that managers care about their relative position with respect to the entire economy. We will also discuss a number of variations in utility specification in Appendix C. Lastly, we point out that the type of preferences we consider can be constructed from Maccheroni, 
Marinacci, and Rustichini (2011).

\subsection{Firm value}

The firm's terminal value at time $t=2$ is given by

$$
V_{i}=\pi a_{i}+\left(\kappa_{1} a_{i}+\kappa_{2}\right)\left(\tilde{m}+\eta_{i}\right)
$$

where $\kappa_{1} \geq 0, \kappa_{2} \geq 0, \pi>0$ represents the manager's productivity per unit of effort; $\tilde{m} \sim N\left(0, \sigma_{m}^{2}\right)$ is an aggregate shock that affects all firms; $\eta_{i} \sim N\left(0, \sigma_{\eta}^{2}\right)$ is firm $i$ 's idiosyncratic shock; and $\tilde{m}$ and $\eta_{i}$ are independent of each other.

Similar to Feltham and Wu (2001) and Ozdenoren and Yuan (2015), we assume that the manager's effort affects the firm's exposure to productivity shocks, represented by $\kappa_{1} a_{i}+\kappa_{2}$. Tying firm risk to managerial effort captures the idea that productive effort by managers can be crucial in implementing investment projects. That is, the manager may exert effort by undertaking a large number of investment opportunities, which consequently increases firm risk, as the success of these projects depends on the state realization. The case $\kappa_{1}=0$ is the standard case in which the manager's effort influences only the expected firm value and has no effect on firm risk.

By the same token, firm value is jointly determined by both managerial effort $\left(a_{i}\right)$ and firm risk exposure, i.e., $\left(\kappa_{1} a_{i}+\kappa_{2}\right)\left(\tilde{m}+\eta_{i}\right)$. It has been argued in the literature that one objective of managerial compensation is to induce managerial risk-taking actions that increase not only the variance but also the mean of firm value. ${ }^{7}$ Following Sung (1995) and Dittmann and Yu (2011), we assume that there is a first-best firm strategy, $S^{*}\left(a_{i}\right)$, that maximizes firm value given effort. Let $\sigma^{*}\left(a_{i}\right)=\sigma\left(S^{*}\left(a_{i}\right)\right)$ denote the minimum firm risk that is associated with this strategy. Then $\left(\sigma_{i}^{*}, a_{i}\right)$ represents an efficiency frontier in the manager's opportunity set. To increase value above $\left(\sigma_{i}^{*}, a_{i}\right)$, the manager will have to take more positive-NPV projects, which can be operationalized by allowing the manager to choose a single action $\left(a_{i}\right)$ that affects both the mean and variance of firm value, as described in (2). In that sense, managerial effort in our model is interpreted as effort related to firm investments. The importance of this investment-related effort is particularly

\footnotetext{
${ }^{7}$ For example, risk-taking incentives are generally used to argue that options can be more efficient than stocks (Dittmann and Yu (2011) and Feltham and Wu (2001)).
} 
pronounced in young, growth firms, such as those in the high-tech or knowledge-based industries, in which managers make significant investments in research and development activities.

\subsection{Compensation contract}

As is customary in the literature, we restrict our attention to linear contracts. ${ }^{8}$ We also assume that the component of firm value that depends on the aggregate shock is observable and contractible. That is, shareholders can gauge the part of firm value caused by the aggregate shock $(\tilde{m})$ and may pay the manager separately for this market-determined performance beyond managerial control if they so choose. We refer to the aggregate shock as the luck shock throughout the rest of the paper to be consistent with the related empirical literature, which uses industrial or economy-wide events to proxy for luck.

Standard principal-agent theory suggests that a manager should be paid relative to a benchmark that removes the effect of market or sector performance on the firm's own performance. However, it has been argued that such indexation is not observed in the data; that is, executives can enjoy "pay-for-luck" as well as "pay-for-performance." As we are interested in examining the rationale for pay-for-luck, we focus on the case in which the luck component of firm value can be filtered out. ${ }^{9}$ In particular, we decompose firm value into two components:

$$
V_{i}=\left(V_{i}-\bar{V}\right)+\bar{V}
$$

where $\bar{V} \equiv\left(\kappa_{1} \bar{a}+\kappa_{2}\right) \tilde{m}$ represents the market-wide component of firm value that is caused by luck; $\bar{a}$ is the average effort choice by all other managers. ${ }^{10}$ The residual, $\left(V_{i}-\bar{V}\right)$, represents the firm-specific component of firm value. We call $\bar{V}$ the "luck component."

The compensation contract of the manager at firm $i$ then takes the following form:

$$
w_{i}=\alpha_{i}+\beta_{i}\left(V_{i}-\bar{V}\right)+\gamma_{i} \bar{V}
$$

\footnotetext{
${ }^{8}$ Many papers specify the linear form of contracts for tractability (e.g., Holmstrom and Tirole (1993), Jin (2002), Oyer (2004), and Bolton, Scheinkman and Xiong (2006)).

${ }^{9}$ In a model where the luck component of firm value cannot be disentangled from the total firm value, pay-for-luck arises mechanically.

${ }^{10} \mathrm{It}$ is the same as the average effort of all managers in equilibrium, because every manager is identical and infinitely small.
} 
that is,

$$
w_{i}=\alpha_{i}+\beta_{i}\left[V_{i}-\left(\kappa_{1} \bar{a}+\kappa_{2}\right) \tilde{m}\right]+\gamma_{i}\left(\kappa_{1} \bar{a}+\kappa_{2}\right) \tilde{m}
$$

where $\alpha_{i} \geq 0$ denotes the base salary, $\beta_{i} \geq 0$ represents the pay-performance sensitivity, and $\gamma_{i} \geq 0$ measures the load of managerial pay on luck shocks. Expanding the space of $\gamma_{i}$ to allow for negative values does not affect our main results (discussed in Appendix B). $\bar{a}$ is the average effort choice by all other managers. Note that for each individual firm, the average effort by all other managers, $\bar{a}$, is taken as given and is not influenced by the individual manager whose contract is under consideration. As the continuum of firms and managers are identical, in equilibrium compensation contracts are identical in all firms: $\alpha_{i}=\alpha, \beta_{i}=\beta, \gamma_{i}=\gamma, a_{i}=\bar{a}, \forall i \in[0,1]$. A positive loading on the luck component - a positive $\gamma_{i}$ — implies the use of pay-for-luck in a firm, which is consistent with the empirical literature. ${ }^{11}$

The exponential utility, normally distributed shocks, and linear payoffs yield a mean-variance equivalence in our model. That is, the certainty equivalent of the manager's expected utility in our model is expressed as follows:

$$
C E_{i}=E\left[w_{i}-\tilde{w}\right]-\frac{1}{2} \lambda \operatorname{Var}\left[w_{i}-\tilde{w}\right]-\frac{1}{2} a_{i}^{2}
$$

\subsection{A partial-equilibrium regime}

As a prelude to studying the full-fledged general equilibrium of contracting, we first analyze the contracting problem for one firm in a partial equilibrium setting, taking all the other firms' contracts as given. In the next section, we turn to studying a general Nash equilibrium in which all firms choose contracts simultaneously and act optimally given other firms' strategies.

Following Grossman and Hart (1983), we fix the target effort $\left(a_{i}\right)$ in the first stage when solving for the optimal contract. Risk-neutral shareholders in a firm, indexed by $i$, choose a linear contract (that is, $\alpha_{i}, \beta_{i}, \gamma_{i}$ ) that minimizes the expected cost of implementing the target effort, with the equilibrium feature that average effort equals target effort $\bar{a}=a_{i}{ }^{12}$ The optimal effort is

\footnotetext{
${ }^{11}$ In the model, we have assumed identical firms and managers for simplicity. When firms and managers are heterogeneous, we can use a weighted-average effort choice by all the managers to filter out the luck component from firm value.

${ }^{12}$ According to Grossman and Hart (1983), we will find the cheapest contract to implement any effort $a_{i}$ in the first stage. Given any $a_{i}, \bar{a}$ is actually a parameter chosen by the shareholders to correctly filter out the luck component from the manager's payoff. Thus, $a_{i}=\bar{a}$ always holds in solving for both the first and second stage problems. Later
} 
subsequently solved in the second stage in Section 3.2.

We show in Appendix A that managerial relative concerns, characterized by $\tilde{w}$, can be expressed as

$$
\tilde{w}=h_{l} W+h_{s} M \tilde{m}
$$

where $W=\alpha+\beta \pi \bar{a}$ is the expected average pay of executive peers, and $M=\gamma\left(\kappa_{1} \bar{a}+\kappa_{2}\right)$ is the average sensitivity of others' pay to luck shocks, where $\{\alpha, \beta, \gamma\}$ denote the cash compensation, payfor-performance, and pay-for-luck in the optimal contract all (identical) firms use in equilibrium. Here, $\bar{a}$ is the average effort choice by all other managers, which also equals the effort choice of each manager in equilibrium. With this expression of $\tilde{w}$, we solve for the manager's effort choice below, given his own contract.

Lemma 1. Given the contract $\left(\alpha_{i}, \beta_{i}, \gamma_{i}\right)$, the effort taken by the manager is

$$
a_{i}=\frac{\beta_{i} \pi-\lambda\left[\beta_{i} \kappa_{1}\left(\gamma_{i}\left(\kappa_{1} \bar{a}+\kappa_{2}\right)-h_{s} M-\beta_{i} \kappa_{1} \bar{a}\right) \sigma_{m}^{2}+\beta_{i}^{2} \kappa_{1} \kappa_{2} \sigma_{\eta}^{2}\right]}{1+\lambda \beta_{i}^{2} \kappa_{1}^{2}\left(\sigma_{m}^{2}+\sigma_{\eta}^{2}\right)} .
$$

Suppose the manager cares about his peers' pay structure $\left(h_{s}>0\right)$ : the manager is concerned about the possible state-contingent pay differential, that is, how his pay relative to his executive peers varies depending on the realization of luck shocks. It is straightforward to see from Lemma 1 that other managers' pay-for-luck (i.e., $M$ ) has an effort-inducing effect on an individual manager: When executive peers are paid for luck (i.e., $M>0$ ), exerting effort increases the exposure of the manager's pay to luck shocks and effectively helps the manager maintain his relative status during market fluctuations. We formally state this incentivizing effect below, which will be a key mechanism that supports a general equilibrium with pay-for-luck to be analyzed in the next section.

Corollary 1. The manager's equilibrium effort is increasing in other managers' pay-for-luck: $\frac{\partial a_{i}}{\partial M}>0$ if $\kappa_{1}>0$.

Shareholders face a trade-off when deciding whether to pay the manager for luck, taking all other firms' pay as given. On the one hand, when executive peers are paid for luck (i.e., $M>0$ ), tying managerial pay to luck can mitigate this manager's net exposure to fluctuations in relative on, we show that only symmetric equilbria exist. Therefore, $\bar{a}$ will equal to the average (target) effort in equilibrium. 
compensation, which reduces the associated risk premium. That is, if other managers' compensation fluctuates with the market, the manager with relative wealth concerns worries about falling behind his peers during market fluctuations; giving the manager exposure to the market component thus provides insurance against a state-contingent compensation shortfall relative to other managers. On the other hand, this insurance effect lowers managerial incentives to exert effort as a means to catch up with peers (Lemma 1). When $h_{s} M$ is not too small, the positive effect of pay-for-luck dominates, rendering pay-for-luck optimal in this case. This argument establishes the following result.

Proposition 1. Taking other firms' contracts as given, there exists a threshold $K \geq 0$ such that it is optimal to pay the manager for luck in the firm (i.e., $\gamma_{i}>0$ ) if and only if $h_{s} M>K$. Moreover, $K=0$ if and only if $\kappa_{1}=0$.

When $\kappa_{1}=0$, that is, the manager's effort does not affect the firm's exposure to luck shocks, managerial effort incentives are not affected by their relative considerations and therefore are not mitigated by the insurance against a pay shortfall that is provided by pay-for-luck. The associated reduction in the required risk premium thus makes it optimal to pay the manager for luck as long as he cares about his peers' pay structure $\left(h_{s}>0\right)$ and other managers are paid for luck $(M>0)$.

Note that even if executive peers are paid for luck, it is not optimal to include pay-for-luck in compensation if the manager cares only about the level of his pay relative to his peers. That is, managerial desire to keep up with his peers' pay level does not make pay-for-luck optimal. We can see from Lemma 1 that when $h_{s}=0$, pay-for-luck $\left(\gamma_{i}\right)$ reduces effort incentives - only the disincentivizing effect remains. In this case, it is efficient to avoid using pay-for-luck, because it increases the manager's risk exposure. Therefore, when the manager does not care about his peers' pay structure, an optimal contract does not pay the manager for luck even if other firms do choose to pay for luck.

When other firms do not pay for luck or the manager does not care about other managers' pay structure, managerial relative concerns are not contingent on the realization of luck shocks. Therefore, an optimal contract that avoids paying a risk premium to the manager never involves pay-for-luck. We summarize the results in Lemma 2. 
Lemma 2. If $h_{s}=0$ or $M=0$, then $\gamma_{i}=0$.

Here, we take executive peers' pay as given and find that pay-for-luck may arise if executive peers are paid for luck. However, why are some managers paid for luck in the first place? To gain insight into the economic trade-off that gives rise to pay-for-luck in practice, we next turn to a general-equilibrium setting in which all firms decide their pay structure simultaneously.

\section{Efficient contracting in a general equilibrium}

What happens when all firms set their managerial pay simultaneously? In this section, we study the interaction of managerial status concerns and risk-taking in the context of a general equilibrium of optimal contracting. In the proof of Proposition 2 and Proposition 4, we show that given other firms' contracts, each firm has a unique optimal target effort and a unique optimal contract to implement the effort. Therefore, the model only has symmetric equilibria. We show that there exists an equilibrium that is characterized by pay-for-luck with increased risk-taking.

\subsection{Pay-for-luck}

Here we solve for the Nash equilibrium in which each firm chooses the optimal pay contract, taking into account other firms' compensation schedule. Recall that the value of each firm is given by

$$
V_{i}=\pi a_{i}+\left(\kappa_{1} a_{i}+\kappa_{2}\right)\left(\tilde{m}+\eta_{i}\right), \forall i \in[0,1]
$$

If $\kappa_{1}>0$, productive effort exerted by the manager also increases the firm's exposure to risk. That is, diligent managers undertake more positive-NPV projects, which also leads the firm value to be more exposed to fluctuations in the underlying state. $\kappa_{1}=0$ corresponds to the case in which managerial effort does not affect firm risk. In order to disentangle the effects on pay structure when managerial effort influences firm risk, we consider two cases: $\kappa_{1}=0, \kappa_{2}>0$ and $\kappa_{1}>0, \kappa_{2}=0 .{ }^{13}$

\footnotetext{
${ }^{13}$ We also focus on the case in which $h_{s} \neq 1 . h_{s}=1$ corresponds to a trivial case where the exposure of a manager's own compensation to the luck shock and his disutility from his peers' pay-for-luck (due to relative wealth concerns) are exactly canceled out. Therefore, the manager's expected utility is independent of aggregate risk $\sigma_{m}^{2}$. When $\kappa_{1}=0, \kappa_{2}>0$, and $h_{s}=1$, any $\gamma$ can be an equilibrium. When $\kappa_{1}>0, \kappa_{2}=0$, and $h_{s}=1$, $\gamma$ will be infinity in an equilibrium.
} 
We show that when managerial relative wealth concerns are sufficiently strong and managerial effort affects firm risk, there is a general-equilibrium outcome in which optimal contracts exhibit properties of pay-for-luck: when other firms are expected to pay their managers for luck, paying a manager for luck provides insurance against a compensation shortfall relative to executive peers and reduces the required risk premium in compensation. These results are summarized below.

Proposition 2. Suppose that $\kappa_{1}>0, \kappa_{2}=0$, and $h_{s} \neq 1$.

1) If $h_{s}<1$, then there exists only one equilibrium, in which $\gamma=0$;

2) If $h_{s}>1$, then there exist two equilibria. In one equilibrium, $\gamma=0$; in the other equilibrium, $\gamma>0$. Shareholders' payoff is increasing in $\sigma_{m}^{2}$ in the pay-for-luck equilibrium, and it is greater than that in the no-pay-for-luck equilibrium as long as $\sigma_{m}^{2}>0$.

Interestingly, pay-for-luck has an effort-inducing effect in equilibrium: When managerial effort is necessary in implementing projects (i.e., $\kappa_{1}>0$ ), a higher effort increases the exposure of managerial pay to fluctuations in luck shocks. If other managers are paid for luck, higher effort can help the manager catch up with his peers. Thus, managerial relative wealth concerns provide additional incentives for the manager to exert effort in this case (Corollary 1). This mechanism supports the existence of an equilibrium in which shareholders in all firms tie managerial pay to luck.

Relative wealth concerns on the part of managers thus create a potential source of value for shareholders by committing managers to exert effort. We find that the associated benefits of this effort-inducing mechanism increase shareholder payoff in the pay-for-luck equilibrium beyond that in the no-pay-for-luck equilibrium (part 2 of Proposition 2). There is actually also a simple argument for this result: the shareholders can always set $\gamma_{i} \kappa_{1} \bar{a}=h_{s} M$ (i.e., exactly net out the manager's exposure to luck shocks) and use the same level of pay-for-performance $\left(\beta_{i}\right)$ as in the no-pay-forluck equilibrium to induce desired effort. In so doing, shareholders can obtain a payoff identical to that in the no-pay-for-luck equilibrium, which implies that shareholder payoff in the pay-for-luck equilibrium is at least as good as that in the no-pay-for-luck equilibrium. This argument is based on the assumption that the pay-for-luck equilibrium exists, and we provide the proof for the existence in Appendix D. 
Up to this point, we have shown that relative wealth concerns on the part of managers may enhance firms' ability to discipline managers, generating the use of pay-for-luck that is valuemaximizing in a setting with moral hazard. Shareholders can actually benefit from managers' desire to catch up with executive peers and can improve firm value through efficient contracting. Since the effort-inducing effect of pay-for-luck is stronger when aggregate risk is more volatile, i.e., a higher $\sigma_{m}^{2}$ (by Lemma 1), greater benefits of managerial relative concerns accrue to shareholders during periods of high market fluctuations.

Here, our model has two equilibria: if shareholders of a firm believe that some firms are paying their managers for market movements, they have an incentive to pay for luck as well in order to help their manager keep up with his peers; if a firm expects others not to pay for luck, the shareholders do not find it worthwhile to tie managerial pay to market fluctuations. In equilibrium, these beliefs are self-fulfilling. In Section 4, we show that a unique equilibrium containing pay-for-luck exists when relative wealth concerns are global, in the sense that managers care about their relative positions with respect to the entire economy. We also generalize the specification of relative wealth concerns in a variety of ways in Appendix $\mathrm{C}$ and illustrate the robustness of our results. The results in those generalized versions in Section 4 and Appendix $\mathrm{C}$ also demonstrate that a slight degree of relative considerations can deliver pay-for-luck as an equilibrium compensation strategy.

When managerial effort does not affect the firm's risk exposure $\left(\kappa_{1}=0\right)$, relative wealth concerns do not render additional incentives for effort. Pay-for-luck by all firms cannot be supported as an equilibrium in this case. In equilibrium no manager is paid for luck, as summarized below.

Proposition 3. If $\kappa_{1}=0$ and $h_{s} \neq 1$, there is only one equilibrium in which $\gamma=0$.

When managerial relative concerns are confined within the community of executives, the bundle of a manager's choice of risk with his productive effort is crucial in generating the complementarity in managers' effort, which underpins the use of pay-for-luck in equilibrium. We show in Section 4 that when managerial relative concerns extend beyond an exclusive circle of managers, insurance effect itself is sufficient to generate pay-for-luck. Therefore, a (unique) pay-for-luck equilibrium exists when risk selection is completely independent of effort, that is, the case with $\kappa_{1}=0$. 


\section{$3.2 \quad$ Risk-taking}

In the discussion thus far, we have fixed the target effort and shown that in the pay-for-luck equilibrium, managerial relative wealth concerns provide additional incentives to exert effort. We endogenize the optimal effort in this subsection, and find that the equilibrium effort is indeed higher in the pay-for-luck equilibrium. As productive effort is instrumental in implementing investment projects, firm risk in the pay-for-luck equilibrium also exceeds that in the no-pay-for-luck equilibrium (in which relative wealth concerns do not play a role). We summarize the results for the case in which $\kappa_{1}>0$ and $\kappa_{2}=0$ as follows.

Proposition 4. Suppose that $\kappa_{2}=0$ and $h_{s}>1$. The following holds in the pay-for-luck equilibrium:

1) Given other firms' contracts, each firm has a unique target risk, which is increasing in $\sigma_{m}^{2}$ and is decreasing in $\sigma_{\eta}^{2}$.

2) Firm risk is greater than that in the no-pay-for-luck equilibrium as long as $\sigma_{m}^{2}>0$.

Taking other firms' compensation as given, the greater the aggregate risk, the stronger the incentivizing effects for effort. That is, in response to heightened market fluctuations, the manager is more keen to keep up with peers' contingent pay on luck shocks by also increasing his own exposure to luck shocks through putting forth effort. As a result, both firm risk and equilibrium effort increase with aggregate risk.

As in our no-pay-for-luck equilibrium, standard models argue that as market risk increases, firms take less risk in order to shy away from increased fluctuations in the underlying state. The corporate response to market risk is more nuanced when managers who care about their relative compensation are paid for luck. Managers would then also have incentives to take more investment projects when aggregate risk is pronounced in an effort to catch up with their peers upon lucky market events. Our model thus presents a countervailing force to the impact of aggregate risk on corporate risk-taking and managerial effort.

In a general-equilibrium setting of contracting, the additional effort incentives provided by relative wealth concerns - managers want to catch up with their peers' pay for luck by exerting effort - increase the equilibrium effort and the level of risk tolerated in the pay-for-luck equilibrium. 
That is, relative wealth concerns on the part of managers render pay-for-luck efficient, which, in turn, leads to an increased level of corporate risk-taking.

\subsection{Excessive pay}

We now turn to analyzing the level of managerial pay. We show that the greater managerial concerns are about their pay level relative to their executive peers $\left(h_{l}\right)$, the higher managerial pay is in equilibrium: A small initial increase in compensation in one firm can lead to a magnified pay raise across firms in equilibrium due to the compensation externality. Our model implies that the considerably high level of managerial compensation may be attributed in part to managerial desires to catch up with peers and their frequent social interactions within the executive circle.

Lemma 3. Given a target effort, the expected managerial pay in each firm in equilibrium is represented by

$$
E[w]=\frac{1}{1-h_{l}}(\text { risk premium }+ \text { cost of effort }+\bar{u})
$$

where $\bar{u}$ is the certainty equivalent of the reservation utility.

As excessive risk-taking by financial institutions and overly generous executive pay are widely regarded as key factors in the run-up to the 2007-09 crisis, there have been advocates of pay reductions in the financial services industry. How would these reductions change the equilibrium compensation in our model of relative wealth concerns? In the model, reductions of managerial compensation in a subset of firms would have spillover effects on other firms' pay. We interpret a pay cut in some firms (indexed by $j \neq i$ ) as causing the outside option of the manager, indexed by $i$, to drop, that is, a decrease in $\bar{u}_{i}$. Suppose that some firms (indexed by $j \neq i$ ) impose a pay cut that results in a reduction of $\bar{u}_{i}$ by an amount of $\delta$. As the manager $i$ cares about his pay relative to peers, firm $i$ can further reduce the expected pay of the manager $i$ by $h_{l} \delta$ without compromising managerial effort. Given firm i's move, other firms can also further reduce their managers' pay by $h_{l}\left(\delta+h_{l} \delta\right)$, which leads to further reductions in compensation in firm $i$, and so on and so forth. In equilibrium, the spillover effects caused by relative wealth concerns will eventually lead to a reduction of $\frac{\delta}{\left(1-h_{l}\right)}$ in managerial pay in all firms in equilibrium. 


\subsection{Correlated risk-taking}

A limitation of the model considered so far is that it precludes managers from making a risk selection that is independent of effort decisions. In this section, we consider a more general version of the model that allows managers to choose effort and risk separately, specifically by letting managers make an additional choice of risk above and beyond the risk-taking associated with effort. This extension enables us to explicitly study the role of managerial relative considerations in a firm's choice regarding systemic risk-taking, which proved critical in the wake of the recent financial crisis that highlighted corporate herding behavior, especially corporations' collective exposure to real estate bubbles, as a main source of systemic risk. The literature suggests that correlation of risk across banks is a major prudential concern, as joint failures are socially costly (Acharya (2009); Acharya et al. (2012)).

In particular, we modify the firm value to be

$$
V_{i}=\pi a_{i}+\kappa_{1} a_{i}\left(\tilde{m}+\eta_{i}\right)+\theta_{i} \tilde{m}
$$

where $\theta_{i}$ is an additional choice of firm exposure to luck shocks — the manager can take on extra risk above and beyond the risk-taking associated with effort choice. $\theta_{i}$ can take values in a closed interval $\left[\theta_{l}, \theta_{h}\right]$ with $\theta_{h}>\theta_{l} \geq 0$.

To examine the optimality of pay-for-luck, we allow the luck component of firm value to be filtered out. For illustration purposes, we assume $\kappa_{2}=0$ without loss of generality. The compensation contract of the manager at firm $i$ then takes the following form:

$$
w_{i}=\alpha_{i}+\beta_{i}\left[V_{i}-\left(\kappa_{1} \bar{a}+\bar{\theta}\right) \tilde{m}\right]+\gamma_{i}\left(\kappa_{1} \bar{a}+\bar{\theta}\right) \tilde{m}
$$

where $\bar{a}$ denotes the average effort choice by all other managers, and $\bar{\theta}$ denotes the average risk choice by all other managers. Note that for an individual firm, $\bar{a}$ and $\bar{\theta}$ are taken as given and are not affected by the individual manager whose contract is under consideration. As in the baseline model, in equilibrium compensation contracts are identical across firms, that is, $\alpha_{i}=\alpha, \beta_{i}=\beta, \gamma_{i}=$ $\gamma, a_{i}=\bar{a}, \theta_{i}=\bar{\theta}, \forall i \in[0,1]$, because all firms and managers are identical. 
The certainty-equivalent expected utility of the manager in a firm is then expressed as

$C E_{i}=\alpha_{i}+\beta_{i} \pi a_{i}-h_{l} W-\frac{1}{2} \lambda\left[\left(\beta_{i}\left(\kappa_{1}\left(a_{i}-\bar{a}\right)+\theta_{i}-\bar{\theta}+\gamma_{i}\left(\kappa_{1} \bar{a}+\bar{\theta}\right)-h_{s} M\right)^{2} \sigma_{m}^{2}+\beta_{i}^{2} \kappa_{1}^{2} a_{i}^{2} \sigma_{\eta}^{2}\right]-\frac{1}{2} a_{i}^{2}\right.$.

Recall that in equilibrium $M=\gamma_{i}\left(\kappa_{1} \bar{a}+\bar{\theta}\right)$ holds. We can see that for sufficiently strong relative wealth concerns (i.e., $h_{s}>1$ ), the manager will choose $\theta$ as large as possible given $M$, because from the manager's standpoint, a project of aggregate risk constitutes a source of insurance against falling behind his executive peers. If $\gamma_{i}=0$ (i.e., compensation packages do not pay for luck), it can be verified that any value of $\theta_{i}$, together with $a_{i}=\frac{\beta_{i} \pi}{1+\lambda \kappa_{1}^{2} \sigma_{\eta}^{2} \beta_{i}^{2}}$, can be an equilibrium. In this case we assume that the manager will choose $\theta_{i}=\theta_{l}$.

We are primarily interested in how managers choose correlated risk and how the efficient contract optimally adjusts. Formally, we state the following results:

Proposition 5. Suppose that $h_{s}>1, \kappa_{1}>0, \kappa_{2}=0$. There is an equilibrium that involves payfor-luck, i.e., $\gamma>0$.

1) Managers in the pay-for-luck equilibrium optimally choose $\theta=\theta_{h}$.

2) Shareholders' payoff is greater than that in the no-pay-for-luck equilibrium.

This proposition implies that when managers are concerned about their wealth relative to executive peers, they are inclined to increase their aggregate risk exposure $(\theta)$ and take correlated risks. In addition, an efficient contract that optimally adjusts for managerial relative concerns would allow for increased systemic risk-taking. The rationale for pay-for-luck is the same as in the baseline model: in expectation of pay-for-luck adopted by other firms, tying an individual manager's compensation to market movements insures the manager against fluctuations in relative compensation. In addition, pay-for-luck incentivizes productive effort in equilibrium, as effort is instrumental in selecting investment projects that help managers keep up with their peers whose pay fluctuates with the market. Hence, the key implication that executives' relative wealth concerns lead to the use of pay-for-luck, which enhances shareholder payoff, is also present in this more general version of the model.

More importantly, managerial relative considerations make the correlation of risks - such as companies investing in real estate securities and banks lending to the same sector — more attractive. 
When managerial status concerns are strong, firms herd in their choice of assets and projects, which, in turn, leads to greater systemic risk being built up in the system.

\section{Relative concerns with respect to the economy}

Our analysis thus far has been conducted under the assumption that managers are concerned about their relative compensation in the community of corporate executives. The theoretical literature has also focused on settings in which relative wealth concerns are global, in the sense that agents care about their relative position with respect to the overall wealth in the economy. To capture this broader notion of relative wealth concerns, in this section we modify $\tilde{w}$ to take the following form:

$$
\tilde{w}_{e}=h_{l} \int_{0}^{1} E\left[V_{k}\right] d k+h_{s} \int_{0}^{1}\left(V_{k}-E\left[V_{k}\right]\right) d k
$$

where $V_{k}$ is the value of firm $k$ in the economy. Thus, the first term represents the extent of externality from the absolute wealth level in the overall economy, that is, managers' concerns about their relative position with respect to (the average wealth of) the economy across states. The second term represents the extent of externality from the state-contingent realization of wealth in the economy, that is, managers' concerns about their relative position with respect to (the average wealth of) the economy in each state. It can be shown that $\tilde{w}_{e}$ can be rewritten as $\tilde{w}_{e}=$ $h_{l} W_{e}+h_{s} M_{e} \tilde{m}$, where $W_{e}=\pi \bar{a}$ represents the unconditional average wealth in the economy, and $M_{e}=\kappa_{1} \bar{a}+\kappa_{2}$ represents the average sensitivity of others' wealth to the state of the economy (i.e., luck shocks, $\tilde{m})$. In this analysis, we again consider two cases: $\kappa_{1}>0, \kappa_{2}=0$ and $\kappa_{1}=0, \kappa_{2}>0$.

When relative concerns are global, the insurance provision of pay-for-luck makes it an equilibrium compensation strategy as long as the degree of managerial relative concerns $\left(h_{s}\right)$ is not too small. Pay-for-luck also incentivizes effort and improves shareholders payoff in equilibrium. We summarize the results below.

Proposition 6. Suppose that $\kappa_{1}>0, \kappa_{2}=0$. Fixing the target effort a, there exists a threshold $\hat{h}$ such that

1) if $h_{s}<\hat{h}$, there exists a unique equilibrium with $\gamma=0$;

2) if $h_{s}>\hat{h}$, there exists a unique equilibrium with $\gamma>0$. 
Specifically, $\hat{h}$ goes to 0 as $\kappa_{1}$ approaches 0 . As long as $\kappa_{1}>0$, the shareholders' payoff is higher in the pay-for-luck equilibrium (when $h_{s}>\hat{h}$ ) than in the no-pay-for-luck equilibrium (when $\left.h_{s}<\hat{h}\right)$.

Now we turn to examining the equilibrium risk-taking behavior. Similar to the baseline model, in response to heightened market fluctuation, each manager is more keen to keep up with peers' contingent pay on luck shocks by also increasing his own exposure to luck shocks through putting forth effort. As a result, both firm risk and equilibrium effort increase with aggregate risk.

Proposition 7. Suppose that $\kappa_{1}>0$ and $h_{s}>\hat{h}$. The following holds in the pay-for-luck equilibrium:

1) Given other firms' contracts, each firm has a unique target risk, which is increasing in $\sigma_{m}^{2}$ and decreasing in $\sigma_{\eta}^{2}$.

2) Firm risk is greater than that in the no-pay-for-luck equilibrium (when $h_{s}<\hat{h}$ ).

As in Section 3.4, now we let managers make a risk choice independent of their effort, that is, managers choose $\theta \in\left[\theta_{l}, \theta_{h}\right], \theta_{h}>\theta_{l} \geq 0$, as the firm's additional exposure to luck shocks, an extra risk above and beyond that associated with effort. We show the robustness of model results to this generalized specification of relative concerns below.

Proposition 8. Suppose that $\kappa_{1}>0$ and $h_{s}>\hat{h}$. There exists only one equilibrium with pay-forluck, i.e., $\gamma>0$.

1) Managers in the equilibrium optimally choose $\theta=\theta_{h}$.

2) Shareholders' payoff is greater than that in the no-pay-for-luck equilibrium (when $h_{s}<\hat{h}$ ).

As in our baseline model, tying managerial pay to market movements provides insurance against shortfalls in relative wealth and therefore remains an equilibrium strategy. Proposition 8 also confirms the key trade-off illustrated in Section 4: Pay-for-luck as a value-enhancing compensation arrangement from the shareholders' perspective actually leads to excessive systemic risk built up in the economy.

Proposition 9. Suppose that $\kappa_{1}=0, \kappa_{2}>0$. Fixing the target effort $a$, if $h_{s}>0$, then there exists a unique equilibrium with $\gamma>0$. Moreover, if the manager is allowed to make the additional risk 
choice $\theta$, there exists an infinite number of equilibria with $\gamma>0$, in which any value in $\left[\theta_{l}, \theta_{h}\right]$ can be an equilibrium.

When relative concerns are global, the insurance provision of pay-for-luck always takes effect, as the wealth in the economy is always positively correlated with the aggregate (luck) shock. As a result, even if $\kappa_{1}=0$ (i.e., the incentivizing mechanism goes away), the insurance mechanism itself is sufficient to generate a pay-for-luck equilibrium, which is the unique equilibrium.

The purpose of this section is to demonstrate that if managerial relative considerations extend beyond the community of corporate executives, the insurance provision of pay-for-luck can deliver a unique equilibrium in which all firms tie their managers' compensation to market movements, as long as the degree of relative wealth concerns is not too small.

\section{$5 \quad$ Empirical implications}

\subsection{Pay-for-luck: an efficient contracting view}

Standard contracting models that optimally design incentive pay to maximize firm value imply that shareholders will not reward executives for observable luck, that is, observable changes in firm performance that are beyond the executives' control. However, Bertrand and Mullainathan (2001) find that executives at oil companies receive pay raises when their company performance improves as a result of changes in global oil prices beyond their control. Similar pay-for-luck is also observed at multinational businesses when currency exchange rates fluctuate. In response to the empirical findings, which are inconsistent with a standard principal-agent model, managerial power has been proposed as an alternative paradigm, most notably by Bertrand and Mullainathan (2001) and Bebchuk and Fried (2004). Pay-for-luck has been widely interpreted as suggestive of corporate governance failures.

Motivated by the empirical studies on executive peer effects, ${ }^{14}$ our model shows that when managers are sensitive to the wealth of their peers, pay-for-luck can be consistent with optimal contracting and need not reflect inefficiency. Tying managerial pay to observable industry events provides managers with insurance against compensation shortfalls relative to their peers. In ad-

\footnotetext{
${ }^{14}$ See Bouwman (2013), Shue (2013), Bereskin and Cicero (2013), and Ang, Nagel, and Yang (2013).
} 
dition, pay-for-luck can provide effort incentives in equilibrium and therefore raises shareholder payoff. Should managers be rewarded for luck? Our answer is that the envious ones should.

Our model suggests that pay-for-luck can be especially value-enhancing in industries with strong growth opportunities and in regions with a high concentration of growth firms, such as Silicon Valley, home to various high-tech companies. Managerial effort in growth industries is more likely to be associated with launching new products and undertaking investment opportunities (i.e., a larger $\left.\kappa_{1}\right)$. Recall that paying for luck motivates effort in equilibrium, because productive effort allows executives to catch up with their peers by increasing firm exposure to market fluctuations. Thus, when managers are concerned about executive peers who are in the same industry or geographically close, pay-for-luck as part of equilibrium contracting would have a stronger effort-inducing effect in industries and regions with growth companies.

\subsection{Excessive risk-taking under pay-for-luck}

Compensation practices that incentivize excessive risk-taking, especially of correlated risk, at financial institutions have often been mentioned as one key factor contributing to the recent financial crisis. ${ }^{15}$ The financial crisis renewed interest in the potential for compensation to affect managerial risk-taking, though empirical evidence on the role of compensation in the crisis is mixed (e.g., Fahlenbrach and Stulz (2011); DeYoung, Peng and Yan (2013); Shue and Townsend (2013)). Extant empirical studies on compensation and its implications for risk-taking, however, do not examine pay-for-luck.

Our model uncovers a relation between pay-for-luck and risk-taking. In the presence of relative wealth concerns, tying pay to luck may be an optimal way to efficiently incentivize managerial effort and therefore emerge in compensation practices. In this case, exposing firm value to aggregate fluctuations serves as a source of insurance against falling behind one's executive peers. This mechanism suggests an overlooked link between pay-for-luck and corporate risk-taking, especially of systemic risk, in the cross section of firms.

Interestingly, our model also shows that managers have incentives to take risks more aggressively in periods of heightened aggregate risk. Without relative wealth concerns, a standard model that

\footnotetext{
${ }^{15}$ See, for example, Rajan (2005), Kashyap et al. (2008) and Clementi et al. (2009).
} 
separates the systematic component of firm performance would imply that managerial risk-taking is unrelated to aggregate fluctuations, and, in a model in which the luck component is not separable from the total firm performance, managers would take less risk when aggregate risk is pronounced in order to shield themselves from intensified fluctuations. In contrast to these predictions from existing models, however, managers with relative considerations tend to take more risk, especially correlated risk, precisely when industry prospects are volatile, in an effort to avoid falling behind their executive peers upon industry movements. Our model generates a clear implication for how volatilities in industry fundamentals affect corporate risk-taking that highlights a contrast with existing theories and warrants further empirical examination. More importantly, this mechanism, built on managerial relative wealth concerns, exacerbates the build-up of systemic risk in bad times.

\section{Conclusion}

Economists have long believed that relative wealth concerns are important. Not only are relative considerations prevalent in the population, but they are also likely to be prevalent among corporate executives - those who care about relative wealth that determines social status are more likely to pursue careers as managers. Indeed, empirical studies suggest that peers are a crucial determinant of managerial pay. To date, the theoretical literature has primarily focused on the asset pricing implications relative concerns have and ignored the possibility that such compensation externalities affect corporate policies. That is, relative wealth concerns have been studied independently from incentives.

In this paper, we study the interaction of managerial relative concerns and compensation in the context of managerial effort and investment policy. We show that with managerial relative wealth concerns, tying CEO pay to observable industry events can emerge as an equilibrium compensation strategy and need not necessarily reflect contracting inefficiency. In expectation of pay-for-luck in other firms, tying managerial pay to luck provides insurance to managers against compensation shortfall relative to executive peers during market fluctuations. In addition, when all firms pay for luck, managers may have additional incentives to exert effort in utilizing investment opportunities, which helps them keep up with their peers during industry movements. Our model suggests that 
relative wealth concerns can create one potential source of firm value by committing managers to exert effort, raising shareholder payoff in equilibrium.

It is important to interpret our results with caution. They should not be seen as advocating for paying managers generously for luck. Rather, we argue that criticism of such practices should be balanced by the insurance mechanism that takes effect when managers are concerned about their wealth relative to others. We also show that managerial relative concerns generate incentives to invest aggressively, especially in projects whose payoffs are correlated with peer firms' performance. From a social welfare perspective, the equilibrium compensation strategy that exhibits pay-for-luck represents a trade-off between the build-up of systemic risk and the creation of productive effort.

Our study does not aim to find complete explanations for each of the compensation and risktaking phenomena considered. We paint the set of phenomena with an intentionally broad brush, as our objective is to examine the contracting implications when managers are concerned about their social standing within a closely interacting social circle. Given the mounting empirical evidence for the importance of peer effects on compensation, our goal is to initiate a first attempt to theoretically examine how managerial relative considerations influence compensation structure and risk-taking in a general-equilibrium contracting framework. Certainly more work lies ahead to develop a richer understanding of how managerial relative wealth concerns play a role in structuring executive pay. 


\section{References}

[1] Abel, Andrew, 1990, "Asset Prices under Habit Formation and Catching Up with the Jones," American Economic Review 80, 38-42.

[2] Ang, James, Gregory Nagel, and Jun Yang, 2013, "The Effect of Social Pressures on CEO Compensation," Working Paper.

[3] Barnea, Amir, and Ilan Guedj, 2006, "But Mom, All the Other Kids Have One! - CEO Compensation and Director Networks," Working Paper.

[4] Bebchuk, Lucian, Alma Cohen, and Holger Spamann, 2010, "The Wages of Failure: Executive Compensation at Bear Stearns and Lehman 2000-2008," Yale Journal on Regulation 27, 257282.

[5] Bebchuk, Lucian, and Jesse Fried, 2004, "Pay Without Performance: The Unfulfilled Promise of Executive Compensation," Cambridge, MA: Harvard University Press.

[6] Bereskin, Frederick, and David C. Cicero, 2013, "CEO Compensation Contagion: Evidence from an Exogenous Shock," Journal of Financial Economics 107, 477-493.

[7] Bertrand, Marianne, and Sendhil Mullainathan, 2001, "Are CEOs Rewarded for Luck? The Ones Without Principals Are," Quarterly Journal of Economics 116, 901-932.

[8] Bizjak, John M., Michael Lemmon, and Lalitha Naveen, 2008, "Has the Use of Peer Groups Contributed to Higher Pay and Less Efficient Compensation," Journal of Financial Economics 90, 152-168.

[9] Bolton, Patrick, José Scheinkman and Wei Xiong, 2006, "Executive Compensation and ShortTermist Behaviour in Speculative Markets," Review of Economic Studies 73, 577-610.

[10] Bouwman, Christa H.S., 2013, "The Geography of Executive Compensation," Working Paper.

[11] Chaigneau, Pierre, and Nicolas Sahuguet, 2012, "The Effect of Monitoring on CEO Pay Practices in a Matching Equilibrium," Working Paper.

[12] Chan, Yeung Lewis, and Leonid Kogan, 2002, "Catching Up with the Joneses: Heterogeneous Preferences and the Dynamics of Asset Prices," Journal of Political Economy 110, 1255-1285.

[13] Cheng, Ing-Haw, Harrison Hong, and Jose A. Scheinkman, 2015, "Yesterday's Heroes: Compensation and Risk at Financial Firms," Journal of Finance, 70, 839-879. 
[14] Clementi, G. L., T. Cooley, M. Richardson, and I. Walter, 2009, "Rethinking Compensation in Financial Firms," Restoring Financial Stability, ed. by V. Acharya, and M. Richardson. John Wiley and Sons.

[15] DeMarzo, Peter M., Ron Kaniel, and Ilan Kremer, 2008, "Relative Wealth Concerns and Financial Bubbles," Review of Financial Studies 21, 19-50.

[16] DeMarzo, Peter M. and Ron Kaniel, 2015, "Relative Pay for Non-Relative Performance: Keeping up with the Joneses with Optimal Contracts," Working Paper.

[17] Dittmann, Ingolf, Ernst Maug, and Oliver Spalt 2013, "Indexing Executive Compensation Contracts, " Review of Financial Studies 26, 3182-3224.

[18] Dittmann, Ingolf, and Ko-Chia Yu, 2011, "How Important are Risk-Taking Incentives in Executive Compensation?" Working Paper.

[19] Edmans, Alex, and Xavier Gabaix, 2011, "The Effect of Risk on the CEO Market," Review of Financial Studies 24, 2822-2863.

[20] Fahlenbrach, Rüdiger, and René Stulz, 2011, "Bank CEO Incentives and the Credit Crisis," Journal of Financial Economics 99, 11-26.

[21] Feltham, Gerald A., and Martin GH Wu. 2001, "Incentive Efficiency of Stock versus Options," Review of Accounting Studies 6, 7-28.

[22] Feriozzi, Fabio, 2011, "Paying for Observable Luck," RAND Journal of Economics 42, 387-415.

[23] Frank, Robert H., 1985, "Choosing the Right Pond: Human Behavior and the Quest for Status," Oxford University Press.

[24] Gabaix, Xavier, and Augustin Landier, 2008, "Why has CEO Pay Increased So Much?" Quarterly Journal of Economics 123, 49-100.

[25] Galí, Jordi, 1994, "Keeping Up with the Joneses: Consumption Externalities, Portfolio Choice, and Asset Prices," Journal of Money, Credit and Banking 26, 1-8.

[26] García, Diego, and Günter Strobl, 2011, "Relative Wealth Concerns and Complementarities in Information Acquisition," Review of Financial Studies 24, 169-207.

[27] Gopalan, Radhakrishnan, Todd T. Milbourn, and Fenghua Song, 2010, "Strategic Flexibility and the Optimality of Pay for Sector Performance," Review of Financial Studies 23, 2060-2098.

[28] Grossman, Sanford, and Oliver Hart, 1983, "An Analysis of the Principal-Agent Problem," Econometrica 51, 7-45. 
[29] Himmelberg, Charles, and Glenn Hubbard, 2000, "Incentive Pay and the Market for CEOs: An Analysis of Pay-for-Performance Sensitivity," Working Paper.

[30] Hoffmann, Florian, and Sebastian Pfeil, 2010, "Reward for Luck in a Dynamic Agency Model," Review of Financial Studies 23, 3329-3345.

[31] Holmstrom, Bengt, 1979, "Moral Hazard and Observability," The Bell Journal of Economics 10, 74-91.

[32] Holmstrom, Bengt and Jean Tirole, 1993, "Market Liquidity and Performance Monitoring," Journal of Political Economy 101, 678-709.

[33] Hwang, Byoung-Hyoun, and Seoyoung Kim, 2009, "It Pays to Have Friends," Journal of Financial Economics 93, 138-158.

[34] Jin, Li, 2002, "CEO Compensation, Diversification, and Incentives," Journal of Financial Economics 66, 29-63.

[35] Kashyap, Anil, Raghuram Rajan, and Jeremy Stein, 2008, "Rethinking Capital Regulation," Proceedings of the 2008 Jackson Hole Symposium organized by the Kansas City Fed.

[36] Kovacevic, Savo. 2005, "A Social Comparison Perspective of Executive Remuneration Committees in Australian Companies," Working Paper.

[37] Larcker, David, Scott Richardson, Andrew Seary, and Irem Tuna, 2005, "Back Door Links Between Directors and Executive Compensation," Working Paper.

[38] Maccheroni, Fabio, Massimo Marinacci, and Aldo Rustichini. 2012, "Social decision theory: Choosing within and between groups" The Review of Economic Studies, 79, 1591-1636.

[39] Miglietta, Salvatore, 2014, "Incentives and Relative Wealth Concerns," Quarterly Journal of Finance, 4(04), 1450013.

[40] Ozdenoren, Emre and Kathy Yuan, 2015, "Contractual Externalities and Systemic Risk, " Working Paper.

[41] Noe, Thomas H., and Michael J. Rebello, 2012, "To Each According to Her Luck and Power: Optimal Corporate Governance and Compensation Policy in a Dynamic World," Working Paper.

[42] Oyer, Paul, 2004, "Why Do Firms Use Incentives That Have No Incentive Effects?" Journal of Finance 59, 1619-1650. 
[43] Rajan, Raghuram, 2005, "Has Financial Development Made the World Riskier?," Proceedings, Federal Reserve Bank of Kansas City, August, 313-369.

[44] Steven C. Salop, 1979. "Monopolistic Competition with Outside Goods," The Bell Journal of Economics 10(1) 141-156.

[45] Shue, Kelly, 2013, "Executive Networks and Firm Policies: Evidence from the Random Assignment of MBA Peers," Review of Financial Studies 26, 1401-1442.

[46] Shue, Kelly, and Richard Townsend, 2013, "Swinging for the Fences: Executive Reactions to Quasi-Random Option Grants," Working Paper.

[47] Veblen, Thorstein, 1899, "The Theory of the Leisure Class: An Economic Study of Institutions," New York: Penguin. 


\section{Appendix A. Derivation of $\tilde{w}$}

$\tilde{w}=h_{l} \int_{0}^{1} E\left[w_{k}\right] d k+h_{s} \int_{0}^{1}\left(w_{k}-E\left[w_{k}\right]\right) d k=h_{l} \int_{0}^{1}\left(\alpha+\beta \pi a_{k}\right) d k+h_{s}\left[\int_{0}^{1}\left(\beta\left(\kappa_{1} a_{k}-\kappa_{1} \bar{a}\right)+\gamma\left(\kappa_{1} \bar{a}+\right.\right.\right.$ $\left.\left.\left.\kappa_{2}\right)\right) \tilde{m} d k+\int_{0}^{1} \beta\left(\kappa_{1} a_{k}+\kappa_{2}\right) \eta_{k} d k\right]$. Note that in equilibrium, $a_{k}=\bar{a}$ for all $k \in[0,1]$. So $\tilde{w}=$ $h_{l} W+h_{s} M \tilde{m}+h_{s} \beta\left(\kappa_{1} \bar{a}+\kappa_{2}\right) \int_{0}^{1} \eta_{k} d k$. Since $\left(\eta_{k}\right)_{k \in[0,1]}$ are identically distributed and independent of each other, by the law of large numbers, $\int_{0}^{1} \eta_{k} d k$ converges to 0 almost surely. So $\tilde{w}=h_{l} W+h_{s} M \tilde{m}$.

\section{Appendix B. Allowing for negative $\gamma$}

In the main paper, we restrict $\gamma$ (loading on luck) to be bounded below by zero, due to empirical relevance; empirical studies have documented compensation practice that pays managers for positive changes in firm performance beyond managerial control, and we do not observe firms penalizing managers for market upswings after all. For theoretical generality, in this section we allow for negative $\gamma$, that is, a negative exposure to luck shocks, and re-derive our main results. When managerial relative considerations are confined within the community of executives, we modify Proposition 2 to Proposition 10, stated below, that incorporates a choice of negative $\gamma$.

Proposition 10. Suppose that managers are only concerned about their peer executives' pay and $\kappa_{1}>0, \kappa_{2}=0$, and $h_{s} \neq 1$.

1) If $h_{s}<1$, then there exists two equilibria. In one equilibrium, $\gamma=0$; in the other equilibrium, $\gamma<0$.

2) If $h_{s}>1$, then there exist two equilibria. In one equilibrium, $\gamma=0$; in the other equilibrium, $\gamma>0$. Shareholders' payoff is increasing in $\sigma_{m}^{2}$ in the pay-for-luck equilibrium, and it is greater than that in the no-pay-for-luck equilibrium as long as $\sigma_{m}^{2}>0$.

As we have argued in the main text, when $\kappa_{1}>0$, relative concerns incentivize the manager to exert effort as long as his net exposure to the luck shock is negative. In the model where the manager is only concerned about his peer executives' pay, his net exposure is $\left(1-h_{s}\right) \gamma \kappa_{1} \bar{a}$. Therefore, our main result (an equilibrium with $\gamma>0$ exists) stays unchanged, and the shareholders would set a negative $\gamma$ to generate the effort incentivizing mechanism in the case when $h_{s}<1$.

By the same token, when the manager is concerned about the entire economy, the shareholders would set a negative $\gamma$ to generate the effort-incentivizing mechanism when $h_{s}<\hat{h}$. In all the other cases, the results remain the same as in the main text. We summarize the results below.

Proposition 11. Suppose that $\kappa_{1}>0, \kappa_{2}=0$. Fixing the target effort a, there exists a threshold $\hat{h}$ such that 
1) if $h_{s}<\hat{h}$, there exists a unique equilibrium with $\gamma<0$;

2) if $h_{s}=\hat{h}$, there exists a unique equilibrium with $\gamma=0$;

3) if $h_{s}>\hat{h}$, there exists a unique equilibrium with $\gamma>0$.

Specifically, $\hat{h}$ goes to 0 as $\kappa_{1}$ approaches 0 . As long as $\kappa_{1}>0$, the shareholders' payoff is higher in the pay-for-luck equilibrium (when $h_{s}>\hat{h}$ ) than in the no-pay-for-luck equilibrium (when $\left.h_{s}=\hat{h}\right)$.

When $\kappa_{1}=0$, there is no effort-incentivizing mechanism, so all the results in this case are unchanged. As can be seen in the main text, we are primarily interested in the cases when $h_{s}$ is not too small. So our main results are not affected if $\gamma$ is allowed to be negative.

\section{Appendix C. Generalizing relative concerns with respect to peers}

In the baseline model in Section 3, the relative wealth concerns consist of two components: the average level of others' wealth across states and the average level of all others' wealth in each state. In a closely interacting circle of executives, a manager with relative wealth concerns might care about his wealth relative to not only an average level, but also each individual manager's. The wealth of each and every other manager in each state can be an essential element in managerial relative concerns. To capture this additional component, we consider some generalized specifications of relative wealth concerns in this section. We show that our results in the baseline model are robust to generalizations of managerial relative concerns with respect to their peers. ${ }^{16}$

\section{Each and every other manager}

To capture managers' concerns about each and every other individual manager, we generalize the specification of relative wealth concerns using the following form: ${ }^{17}$

$$
\tilde{w}=h_{l} \int_{0}^{1} E\left[w_{k}\right] d k+h_{s} \int_{0}^{1} f(k)\left(w_{k}-E\left[w_{k}\right]\right) d k
$$

where $f(k) \geq 0$ denotes the differential weighting an individual manager, indexed by $i$, attaches to his peer indexed by $k \neq i$. That is, managers are concerned about each individual peer's pay and exhibit a varying degree of "envy" toward each and every other manager. The insurance provision and effort-inducing effects of pay-for-luck are robust to this generalization of relative

\footnotetext{
${ }^{16}$ Our results hold as long as the normality of $\tilde{w}$ is preserved, which is required for tractability.

${ }^{17}$ An alternative form, $\tilde{w}=h_{l} \int_{0}^{1} E\left[w_{k}\right] d k+h_{s} \int_{0}^{1}\left(w_{k}-E\left[w_{k}\right]\right) d k+h_{s} \int_{0}^{1} f(k)\left(w_{k}-E\left[w_{k}\right]\right) d k$, whose first two components coincide with $\tilde{w}$ in the baseline model, collapses to the current form.
} 
wealth concerns; therefore, shareholders across firms consequently find it optimal to pay managers for luck, which raises shareholder value in equilibrium. We formalize this claim in Proposition 12.

Proposition 12. Suppose that $\kappa_{1}>0, \kappa_{2}=0, f(k)$ is bounded for $k \in[0,1]$, and $h_{s} \int_{0}^{1} f(k) d k \neq 1$ holds.

1) If $h_{s} \int_{0}^{1} f(k) d k<1$, there exists only one equilibrium, in which $\gamma=0$;

2) If $h_{s} \int_{0}^{1} f(k) d k>1$, there exist two equilibria. In one equilibrium, $\gamma=0$; in the other equilibrium, $\gamma>0$. Shareholders' payoff in the pay-for-luck equilibrium is greater than that in the no-pay-for-luck equilibrium.

Managers can weigh their peers using a variety of criteria, that is, $f(k)$ can take various forms depending on managerial preferences. To provide some economic interpretation of managerial relative considerations, we discuss a few plausible forms of $f(k)$ below.

\section{Example 1: Proximity}

It is natural to think that managers benchmark themselves more against their peers who are geographically close or in similar industries than against those in distant locations and businesses. Weighing executive peers based on proximity implies that the $f(k)$ used by a manager is inversely related to his distance from any other manager, denoted by $d(i, k)$ for any $k \neq i$. This distance can represent the extent of separation in the nature of industries, geographic locations, and network relations. For example, following Salop's circular city (1979) model, we can assume that a continuum of managers are uniformly distributed on a circle with a unit diameter. Then one possible form of $f(k)$ would be $f(k)=1-d(i, k)$, and $d(i, k)=\frac{\psi \pi}{360}$ denotes the arc length between the manager under consideration, indexed by $i$, and any other manager, indexed by $k \neq i$, where $\psi$ is the angle in degrees.

\section{Example 2: Similarity}

Managers may have a stronger tendency to compare themselves with peers who have a similar background in education, ethnicity, alumni association, age and tenure year, among others. Let us use a vector $\mathcal{X}$ to denote the personal characteristics managers identify themselves by and use to select their reference peers. The weighting function $f(k)$ used by a manager, indexed by $i$, in this case can be any monotonically decreasing function of a pairwise similarity score, proxied by $\left|\mathcal{X}_{k}-\mathcal{X}_{i}\right|$, for any $k \neq i$.

\section{Example 3: Quantiles}

Managers may also care differently about their peers in varying quantiles of the pay distribution. For example, managers may be more concerned about the top percentile compared to the bottom percentile and exhibit relatively stronger envy toward certain subgroups depending on the 
ranking in compensation. This suggests that the reference points in managerial relative wealth concerns include not only the average level of their peers' pay, but also other distributional moments. Specifically, we can write $f(k)$ as a step function: $f(k)=f_{k}$ for the compensation of managers in the $k$ th percentile, $\forall k \in\{1,2, \cdots, 100\}$.

\section{Position oneself}

In the previous subsection, we analyze the optimality of pay-for-luck when managers care about each and every other manager in the executive circle. Psychology theory suggests that individuals identify their relative income position and may only envy up. ${ }^{18}$ This tendency suggests that managers may exclusively exhibit relative considerations toward a selected subset of their peers - for example, the better-paid peers. In this case, the weighting function $f(k)$ used by a manager indexed by $i$ is represented by an indicator function $I_{\left\{w_{k}>w_{i}\right\}}$ that equals 1 if $w_{k}>w_{i}$ and 0 otherwise. Distinct from the specifications of $f(k)$ in Section 6, which are deterministic functions, $f(k)$ in this case becomes a random variable that depends on realized pay. We show that $\tilde{w}$ can be simplified to

$\tilde{w}=h_{l} W+\frac{h_{s}}{2} M \tilde{m}+$ constant in this case. Because of the same mechanisms in the baseline model, we obtain similar contracting results and formalize them below.

Proposition 13. Suppose that $\kappa_{1}>0, \kappa_{2}=0$, and $h_{s} \neq 2$.

1) If $h_{s}<2$, then there exists only one equilibrium, in which $\gamma=0$;

2) If $h_{s}>2$, then there exist two equilibria. In one equilibrium, $\gamma=0$; in the other equilibrium, $\gamma>0$. Shareholders' payoff in the pay-for-luck equilibrium is greater than that in the no-pay-for-luck equilibrium.

\section{Leading managers}

So far in this section, we have studied various cases in which each individual firm and manager are infinitely small such that each individual's compensation contract does not affect other firms and managers, as in the baseline model. In reality, there may be some leading managers, whose compensation contracts can affect others. To capture this possibility, we adopt an alternative specification of relative wealth concerns as in the following form:

$$
\tilde{w}=h_{l} \int_{0}^{1} E\left[w_{k}\right] d k+h_{s} \int_{0}^{1}\left(w_{k}-E\left[w_{k}\right]\right) d k+\sum_{j=i_{1}, \cdots, i_{n}} h_{j}\left(w_{j}-E\left[w_{j}\right]\right) .
$$

\footnotetext{
${ }^{18}$ See, for example, Fiske, "Envy Up, Scorn Down: How Comparison Divides Us," Am Psychol. 2010, 65(8).
} 
The first two components are identical to the specification of $\tilde{w}$ in the baseline model, and the third component consists of the pay of some individual managers, called leading managers hereafter, where $h_{j}$ represents a manager's concern about his pay relative to leading managers indexed by $j$ for $j \in\left\{i_{1}, \cdots, i_{n}\right\}, \forall n$.

Now leading managers' compensation contracts would actually have an effect on other managers in the executive circle. The leading firms take this into account when designing their compensation contracts, which adds complications in deriving a closed-form solution. For tractability, we consider the case with one leading manager, indexed by 0 . This leading manager's relative wealth concerns, denoted by $\tilde{w}_{0}$, remain unchanged from those in the baseline model:

$$
\tilde{w}_{0}=h_{l} \int_{0}^{1} E\left[w_{k}\right] d k+h_{s} \int_{0}^{1}\left(w_{k}-E\left[w_{k}\right]\right) d k .
$$

For the rest of the managers, indexed by $i \in(0,1]$, their relative wealth concerns are expressed as

$$
\tilde{w}=h_{l} \int_{0}^{1} E\left[w_{k}\right] d k+h_{s} \int_{0}^{1}\left(w_{k}-E\left[w_{k}\right]\right) d k+h_{0}\left(w_{0}-E\left[w_{0}\right]\right)
$$

where $h_{0}$ denotes other managers' relative considerations toward the leading manager. Pay-for-luck can remain part of equilibrium contracting and increase shareholder payoff in this case. We state these results in Proposition 14 below.

Proposition 14. Suppose that $\kappa_{1}>0, \kappa_{2}=0, h_{l}$ is small, and $h_{s} h_{0}<1$.

1) If $h_{s}<\frac{1}{1+h_{0}}$, then there exists only one equilibrium in which all managers are not paid for luck.

2) If $h_{s}>\frac{1}{1+h_{0}}$, then there exist two equilibria. In one equilibrium, $\gamma=0$; in the other equilibrium, $\gamma>0$. Shareholders' payoff in the pay-for-luck equilibrium is greater than that in the no-pay-for-luck equilibrium.

\section{Appendix D. Proofs}

\section{Proof of Proposition 1, Lemma 1, and Lemma 2:}

The CEO's compensation is $w_{i}=\alpha_{i}+\beta_{i}\left[\pi a_{i}+\left(\kappa_{1} a_{i}+\kappa_{2}\right) \eta\right]+\left[\beta_{i} \kappa_{1}\left(a_{i}-\bar{a}\right)+\gamma_{i}\left(\kappa_{1} \bar{a}+\kappa_{2}\right)\right] \tilde{m}$. So we can calculate that the certainty-equivalent of the expected utility is $C E=\alpha_{i}+\beta_{i} \pi a_{i}-$ $h_{l} W-\frac{1}{2} \lambda\left[\left(\beta_{i} \kappa_{1}\left(a_{i}-\bar{a}\right)+\gamma_{i}\left(\kappa_{1} \bar{a}+\kappa_{2}\right)-h_{s} M\right)^{2} \sigma_{m}^{2}+\beta_{i}^{2}\left(\kappa_{1} a_{i}+\kappa_{2}\right)^{2} \sigma_{\eta}^{2}\right]-\frac{1}{2} a_{i}^{2}$. Taking the first-order condition yields $\beta_{i} \pi-\lambda\left[\beta_{i} \kappa_{1}\left(\beta_{i} \kappa_{1}\left(a_{i}-\bar{a}\right)+\gamma_{i}\left(\kappa_{1} \bar{a}+\kappa_{2}\right)-h_{s} M\right) \sigma_{m}^{2}+\beta_{i}^{2} \kappa_{1}\left(\kappa_{1} a_{i}+\kappa_{2}\right) \sigma_{\eta}^{2}\right]-a_{i}=0$, 
which implies that

$$
a_{i}=\frac{\beta_{i} \pi-\lambda\left[\beta_{i} \kappa_{1}\left(\gamma_{i}\left(\kappa_{1} \bar{a}+\kappa_{2}\right)-h_{s} M-\beta_{i} \kappa_{1} \bar{a}\right) \sigma_{m}^{2}+\beta_{i}^{2} \kappa_{1} \kappa_{2} \sigma_{\eta}^{2}\right]}{1+\lambda \beta_{i}^{2} \kappa_{1}^{2}\left(\sigma_{m}^{2}+\sigma_{\eta}^{2}\right)}
$$

To minimize the cost of the contract, the base salary $\alpha_{i}$ must be set such that the participation constraint is binding. Thus, the shareholders' objective is

$$
\min _{\beta_{i}, \gamma_{i}} \frac{1}{2} \lambda\left[\left(\beta_{i} \kappa_{1}\left(a_{i}-\bar{a}\right)+\gamma_{i}\left(\kappa_{1} \bar{a}+\kappa_{2}\right)-h_{s} M\right)^{2} \sigma_{m}^{2}+\beta_{i}^{2}\left(\kappa_{1} a_{i}+\kappa_{2}\right)^{2} \sigma_{\eta}^{2}\right]
$$

subject to (5). Since $a_{i}=\bar{a}$ in equilibrium, the objective function can be simplified to

$$
\min _{\beta_{i}, \gamma_{i}} \frac{1}{2} \lambda\left[\left(\gamma_{i}\left(\kappa_{1} \bar{a}+\kappa_{2}\right)-h_{s} M\right)^{2} \sigma_{m}^{2}+\beta_{i}^{2}\left(\kappa_{1} a_{i}+\kappa_{2}\right)^{2} \sigma_{\eta}^{2}\right]
$$

subject to (5).

When $h_{s} M=0$, increasing $\gamma_{i}$ from zero to positive will always increase the risk premium and thus increase the cost of the contract. From (5), we can see that increasing $\gamma_{i}$ also has a negative effect on the manager's effort. So $\beta_{i}$ has to rise to induce the target effort as $\gamma_{i}$ increases, which further boosts the cost of the contract. Therefore, when $h_{s} M=0$, the optimal $\gamma_{i}$ equals zero, i.e., no pay-for-luck.

When $h_{s} M>0$, plugging $a_{i}=\bar{a}$ into (5), we can obtain that

$$
\lambda \kappa_{1}\left(\kappa_{1} a_{i}+\kappa_{2}\right) \sigma_{\eta}^{2} \beta_{i}^{2}-\left[\pi-\lambda \kappa_{1}\left(\gamma_{i}\left(\kappa_{1} \bar{a}+\kappa_{2}\right)-h_{s} M\right) \sigma_{m}^{2}\right] \beta_{i}+a_{i}=0 .
$$

Thus, we can solve that the optimal $\beta_{i}$ is

$$
\beta_{i}=\frac{2 a_{i}}{\left[\pi-\lambda \kappa_{1}\left(\gamma_{i}\left(\kappa_{1} \bar{a}+\kappa_{2}\right)-h_{s} M\right) \sigma_{m}^{2}\right]+\sqrt{\left[\pi-\lambda \kappa_{1}\left(\gamma_{i}\left(\kappa_{1} \bar{a}+\kappa_{2}\right)-h_{s} M\right) \sigma_{m}^{2}\right]^{2}-4 \lambda \kappa_{1} a_{i}\left(\kappa_{1} a_{i}+\kappa_{2}\right) \sigma_{\eta}^{2}}} .
$$

We can calculate that $\frac{\partial \beta_{i}}{\partial \gamma_{i}}=\frac{\lambda \kappa_{1}\left(\kappa_{1} \bar{a}+\kappa_{2}\right) \sigma_{m}^{2} \beta_{i}}{\sqrt{\left[\pi-\lambda \kappa_{1}\left(\gamma_{i}\left(\kappa_{1} \bar{a}+\kappa_{2}\right)-h_{s} M\right) \sigma_{m}^{2}\right]^{2}-4 \lambda \kappa_{1} a_{i}\left(\kappa_{1} a_{i}+\kappa_{2}\right) \sigma_{\eta}^{2}}}>0$. Then it is easy to check that the objective function $\frac{1}{2} \lambda\left[\left(\gamma_{i}\left(\kappa_{1} \bar{a}+\kappa_{2}\right)-h_{s} M\right)^{2} \sigma_{m}^{2}+\beta_{i}\left(\gamma_{i}\right)^{2}\left(\kappa_{1} a_{i}+\kappa_{2}\right)^{2} \sigma_{\eta}^{2}\right]$ is a convex function in $\gamma_{i}$. Hence, the optimal $\gamma_{i}$ is positive if and only if the derivative of the objective function w.r.t. $\gamma_{i}$ is negative at $\gamma_{i}=0$, which is equivalent to

$$
-\left(\kappa_{1} \bar{a}+\kappa_{2}\right) h_{s} M+\frac{\lambda \kappa_{1}\left(\kappa_{1} \bar{a}+\kappa_{2}\right)\left(\kappa_{1} a_{i}+\kappa_{2}\right)^{2} \sigma_{\eta}^{2}\left(\left.\beta_{i}\right|_{\gamma_{i}=0}\right)^{2}}{\sqrt{\left(\pi+\lambda \kappa_{1} h_{s} M \sigma_{m}^{2}\right)^{2}-4 \lambda \kappa_{1} a_{i}\left(\kappa_{1} a_{i}+\kappa_{2}\right) \sigma_{\eta}^{2}}}<0 .
$$


Note that the left-hand side in the above inequality is decreasing in $h_{s} M$ and nonnegative at $h_{s} M=0$. Thus, there must exist a cut-off $K \geq 0$ such that the left-hand side in the above inequality is less than zero if and only if $h_{s} M>K$. Moreover, since the left-hand side in the above inequality is positive at $h_{s} M=0$ unless $\kappa_{1}=0$, the cut-off $K$ equals to zero if and only if $\kappa_{1}=0$.

Proof of Proposition 2: When $\kappa_{2}=0$, the shareholders' objective is

$$
\min _{\beta_{i}, \gamma_{i}} \frac{1}{2} \lambda\left[\left(\beta_{i} \kappa_{1}\left(a_{i}-\bar{a}\right)+\gamma_{i} \kappa_{1} \bar{a}-h_{s} M\right)^{2} \sigma_{m}^{2}+\beta_{i}^{2} \kappa_{1}^{2} a_{i}^{2} \sigma_{\eta}^{2}\right]
$$

subject to $a_{i}=\frac{\beta_{i} \pi-\lambda \beta_{i} \kappa_{1}\left(\gamma_{i} \kappa_{1} \bar{a}-h_{s} M-\beta_{i} \kappa_{1} \bar{a}\right) \sigma_{m}^{2}}{1+\lambda \beta_{i}^{2} \kappa_{1}^{2}\left(\sigma_{m}^{2}+\sigma_{\eta}^{2}\right)}$, which can be rewritten as

$$
\lambda \kappa_{1}^{2}\left[\left(a_{i}-\bar{a}\right) \sigma_{m}^{2}+a_{i} \sigma_{\eta}^{2}\right] \beta_{i}^{2}-\left[\pi-\lambda \kappa_{1}\left(\gamma_{i} \kappa_{1} \bar{a}-h_{s} M\right) \sigma_{m}^{2}\right] \beta_{i}+a_{i}=0
$$

Similarly, we can calculate that $\beta_{i}=\frac{2 a_{i}}{\left[\pi-\lambda \kappa_{1}\left(\gamma_{i} \kappa_{1} \bar{a}-h_{s} M\right) \sigma_{m}^{2}\right]+\sqrt{\left[\pi-\lambda \kappa_{1}\left(\gamma_{i} \kappa_{1} \bar{a}-h_{s} M\right) \sigma_{m}^{2}\right]^{2}-4 \lambda \kappa_{1}^{2} a_{i}\left[\left(a_{i}-\bar{a}\right) \sigma_{m}^{2}+a_{i} \sigma_{\eta}^{2}\right]}}$, and $\frac{\partial \beta_{i}}{\partial \gamma_{i}}=\frac{\lambda \kappa_{1}^{2} \bar{a} \sigma_{m}^{2} \beta_{i}}{\sqrt{\left[\pi-\lambda \kappa_{1}\left(\gamma_{i} \kappa_{1} \bar{a}-h_{s} M\right) \sigma_{m}^{2}\right]^{2}-4 \lambda \kappa_{1}^{2} a_{i}\left[\left(a_{i}-\bar{a}\right) \sigma_{m}^{2}+a_{i} \sigma_{\eta}^{2}\right]}}>0$. Thus, it is easy to check that the objective function $\frac{1}{2} \lambda\left[\left(\beta_{i}\left(\gamma_{i}\right) \kappa_{1}\left(a_{i}-\bar{a}\right)+\gamma_{i} \kappa_{1} \bar{a}-h_{s} M\right)^{2} \sigma_{m}^{2}+\beta_{i}\left(\gamma_{i}\right)^{2} \kappa_{1}^{2} a_{i}^{2} \sigma_{\eta}^{2}\right]$ is convex in $\gamma_{i}$. So if there exists an optimal solution with $\gamma_{i}>0$, we must have that at the optimal $\gamma_{i}$,

$$
\left(\frac{\partial \beta_{i}}{\partial \gamma_{i}} \kappa_{1}\left(a_{i}-\bar{a}\right)+\kappa_{1} \bar{a}\right)\left(\beta_{i}\left(\gamma_{i}\right) \kappa_{1}\left(a_{i}-\bar{a}\right)+\gamma_{i} \kappa_{1} \bar{a}-h_{s} M\right) \sigma_{m}^{2}+\frac{\partial \beta_{i}}{\partial \gamma_{i}} \beta_{i} \kappa_{1}^{2} a_{i}^{2} \sigma_{\eta}^{2}=0
$$

Since in equilibrium, $a_{i}=\bar{a}, \gamma_{i}=\gamma$, and $M=\gamma \kappa_{1} \bar{a}$, the left-hand side simplifies to $\kappa_{1}^{2} \bar{a}^{2} \gamma\left(1-h_{s}\right)+$ $\frac{\partial \beta_{i}}{\partial \gamma_{i}} \beta_{i} \kappa_{1}^{2} a_{i}^{2} \sigma_{\eta}^{2}$, which is positive if $h_{s}<1$. So when $h_{s}<1$, there is only one equilibrium, in which $\gamma_{i}=0$.

When $h_{s}>1$, there could be two equilibria. In one equilibrium, we still have $\gamma_{i}=0$ for each firm. In the other equilibrium, $\gamma_{i}>0$. The Lagrangian function (with the Lagrangian multiplier $\rho)$ is

$$
\begin{aligned}
L & =\frac{1}{2} \lambda\left[\left(\beta_{i} \kappa_{1}\left(a_{i}-\bar{a}\right)+\gamma_{i} \kappa_{1} \bar{a}-h_{s} M\right)^{2} \sigma_{m}^{2}+\beta_{i}^{2} \kappa_{1}^{2} a_{i}^{2} \sigma_{\eta}^{2}\right] \\
& -\rho\left[\beta_{i} \pi-\lambda \beta_{i} \kappa_{1}\left(\gamma_{i} \kappa_{1} \bar{a}-h_{s} M-\beta_{i} \kappa_{1} \bar{a}\right) \sigma_{m}^{2}-\left(1+\lambda \beta_{i}^{2} \kappa_{1}^{2}\left(\sigma_{m}^{2}+\sigma_{\eta}^{2}\right)\right) a_{i}\right]
\end{aligned}
$$


Taking the FOC w.r.t. $\beta_{i}$ and $\gamma_{i}$ yields that

$$
\begin{aligned}
& \lambda\left[\kappa_{1}\left(a_{i}-\bar{a}\right)\left(\beta_{i} \kappa_{1}\left(a_{i}-\bar{a}\right)+\gamma_{i} \kappa_{1} \bar{a}-h_{s} M\right) \sigma_{m}^{2}+\beta_{i} \kappa_{1}^{2} a_{i}^{2} \sigma_{\eta}^{2}\right] \\
& =\rho\left[\pi-\lambda \kappa_{1}\left(-2 \kappa_{1} \bar{a} \beta_{i}+\gamma_{i} \kappa_{1} \bar{a}-h_{s} M\right) \sigma_{m}^{2}-2 \lambda \beta_{i} \kappa_{1}^{2}\left(\sigma_{m}^{2}+\sigma_{\eta}^{2}\right) a_{i}\right], \\
& \lambda \kappa_{1} \bar{a}\left(\beta_{i} \kappa_{1}\left(a_{i}-\bar{a}\right)+\gamma_{i} \kappa_{1} \bar{a}-h_{s} M\right) \sigma_{m}^{2}=-\rho \lambda \beta_{i} \kappa_{1}^{2} \bar{a} \sigma_{m}^{2} .
\end{aligned}
$$

Taking the ratio of the two equalities can simplify to

$\left(\beta_{i} \kappa_{1}\left(a_{i}-\bar{a}\right)+\gamma_{i} \kappa_{1} \bar{a}-h_{s} M\right)\left[\pi-\lambda \kappa_{1} \sigma_{m}^{2}\left(\beta_{i} \kappa_{1}\left(a_{i}-\bar{a}\right)+\gamma_{i} \kappa_{1} \bar{a}-h_{s} M\right)-2 \lambda \beta_{i} \kappa_{1}^{2} \sigma_{\eta}^{2} a_{i}\right]=-\lambda \kappa_{1}^{3} \beta_{i}^{2} \sigma_{\eta}^{2} a_{i}^{2}$.

Note that $a_{i}=\frac{\beta_{i} \pi-\lambda \beta_{i} \kappa_{1}\left(\gamma_{i} \kappa_{1} \bar{a}-h_{s} M-\beta_{i} \kappa_{1} \bar{a}\right) \sigma_{m}^{2}}{1+\lambda \beta_{i}^{2} \kappa_{1}^{2}\left(\sigma_{m}^{2}+\sigma_{\eta}^{2}\right)}$ implies that $\pi-\lambda \kappa_{1} \sigma_{m}^{2}\left(\beta_{i} \kappa_{1}\left(a_{i}-\bar{a}\right)+\gamma_{i} \kappa_{1} \bar{a}-h_{s} M\right)=$ $\frac{a_{i}}{\beta_{i}}+\lambda \beta_{i} \kappa_{1}^{2} \sigma_{\eta}^{2} a_{i}$. So $\left(\beta_{i} \kappa_{1}\left(a_{i}-\bar{a}\right)+\gamma_{i} \kappa_{1} \bar{a}-h_{s} M\right)\left(\frac{a_{i}}{\beta_{i}}-\lambda \beta_{i} \kappa_{1}^{2} \sigma_{\eta}^{2} a_{i}\right)=-\lambda \kappa_{1}^{3} \beta_{i}^{2} \sigma_{\eta}^{2} a_{i}^{2}$. Thus, $\beta_{i} \kappa_{1}\left(a_{i}-\right.$ $\bar{a})+\gamma_{i} \kappa_{1} \bar{a}-h_{s} M=-\frac{\lambda \kappa_{1}^{3} \beta_{i}^{3} \sigma_{\eta}^{2} a_{i}}{1-\lambda \beta_{i}^{2} \kappa_{1}^{2} \sigma_{\eta}^{2}}$. Plugging it into $a_{i}=\frac{\beta_{i} \pi-\lambda \beta_{i} \kappa_{1}\left(\gamma_{i} \kappa_{1} \bar{a}-h_{s} M-\beta_{i} \kappa_{1} \bar{a}\right) \sigma_{m}^{2}}{1+\lambda \beta_{i}^{2} \kappa_{1}^{2}\left(\sigma_{m}^{2}+\sigma_{\eta}^{2}\right)}$ yields that

$$
\lambda \kappa_{1}^{2} \sigma_{\eta}^{2} a_{i} \beta_{i}^{2}-\pi \beta_{i}+a_{i}-\frac{\lambda^{2} \kappa_{1}^{4} \sigma_{m}^{2} \sigma_{\eta}^{2} a_{i} \beta_{i}^{4}}{1-\lambda \kappa_{1}^{2} \sigma_{\eta}^{2} \beta_{i}^{2}}=0
$$

Since the risk premium in this case is

$$
\frac{1}{2} \lambda\left[\left(\beta_{i} \kappa_{1}\left(a_{i}-\bar{a}\right)+\gamma_{i} \kappa_{1} \bar{a}-h_{s} M\right)^{2} \sigma_{m}^{2}+\beta_{i}^{2} \kappa_{1}^{2} a_{i}^{2} \sigma_{\eta}^{2}\right]=\frac{1}{2} \lambda \kappa_{1}^{2} a_{i}^{2} \sigma_{\eta}^{2} \beta_{i}^{2}\left[\frac{\lambda^{2} \kappa_{1}^{4} \sigma_{m}^{2} \sigma_{\eta}^{2} \beta_{i}^{4}}{\left(1-\lambda \beta_{i}^{2} \kappa_{1}^{2} \sigma_{\eta}^{2}\right)^{2}}+1\right]
$$

which is increasing in $\beta_{i}$. The optimal $\beta_{i}$ must be the minimum (positive) solution to (6). Let $F\left(\beta_{i}\right)$ denote the left-hand side of $(6)$. Since $F(0)>0$ and $F\left(\sqrt{\frac{1}{\lambda \kappa_{1}^{2} \sigma_{\eta}^{2}}}\right)<0,0<\beta_{i}<\sqrt{\frac{1}{\lambda \kappa_{1}^{2} \sigma_{\eta}^{2}}}$. In equilibrium, $a_{i}=\bar{a}$ and $M=\gamma_{i} \kappa_{1} \bar{a}$, so we can confirm that in this second equilibrium,

$$
\gamma_{i}=\frac{\lambda \kappa_{1}^{2} \beta_{i}^{3} \sigma_{\eta}^{2}}{\left(h_{s}-1\right)\left(1-\lambda \beta_{i}^{2} \kappa_{1}^{2} \sigma_{\eta}^{2}\right)}>0
$$

We use $\beta_{i 0}$ and $\beta_{i \gamma}$ to denote the optimal pay-performance sensitivity in the no-pay-for-luck equilibrium and pay-for-luck equilibrium, respectively. Then $\beta_{i 0}$ is the minimum (positive) solution to the equation $\lambda \kappa_{1}^{2} \sigma_{\eta}^{2} a_{i} \beta_{i}^{2}-\pi \beta_{i}+a_{i}=0,{ }^{19}$ which is $\frac{\frac{\pi}{a_{i}}-\sqrt{\left(\frac{\pi}{a_{i}}\right)^{2}-4 \lambda \kappa_{1}^{2} \sigma_{\eta}^{2}}}{2 \lambda \kappa_{1}^{2} \sigma_{\eta}^{2}} . \beta_{i \gamma}$ is the minimum (positive) solution to (6). Note that $F(0)>0\left(F\left(\beta_{i}\right)\right.$ is the left-hand side of $\left.(6)\right)$, so $\left.\frac{\partial F}{\partial \beta_{i}}\right|_{\beta_{i}=\beta_{i \gamma}}<0$. Since

\footnotetext{
${ }^{19}$ More rigorously, $\beta_{i 0}$ should be the minimum (positive) solution to the equation $\lambda \kappa_{1}^{2}\left[\left(\sigma_{m}^{2}\left(a_{i}-\bar{a}\right)+\sigma_{\eta}^{2} a_{i}\right] \beta_{i}^{2}-\right.$ $\pi \beta_{i}+a_{i}=0$. But since at the first stage the target effort $a_{i}$ is fixed and equals $\bar{a}$ in equilibrium, the equation can be simplified to $\lambda \kappa_{1}^{2} \sigma_{\eta}^{2} a_{i} \beta_{i}^{2}-\pi \beta_{i}+a_{i}=0$.
} 
$\frac{\partial F}{\partial \sigma_{m}^{2}}<0$, by the Implicit Function Theorem, $\left.\frac{\partial \beta_{i}}{\partial \sigma_{m}^{2}}\right|_{\beta_{i}=\beta_{i \gamma}}<0$. Thus, $\beta_{i \gamma} \leq \beta_{i 0}$ with equality holds only when $\sigma_{m}^{2}=0$.

Recall that the risk premium in the pay-for-luck equilibrium is $\frac{1}{2} \lambda \kappa_{1}^{2} a_{i}^{2} \sigma_{\eta}^{2} \beta_{i}^{2}\left[\frac{\lambda^{2} \kappa_{1}^{4} \sigma_{m}^{2} \sigma_{\eta}^{2} \beta_{i}^{4}}{\left(1-\lambda \beta_{i}^{2} \kappa_{1}^{2} \sigma_{\eta}^{2}\right)^{2}}+1\right]$ (with $\beta_{i}=\beta_{i \gamma}$ ), by (6), it can be simplified to $\frac{1}{2} \lambda \kappa_{1}^{2} a_{i}^{2} \sigma_{\eta}^{2} \beta_{i}^{2} \frac{2-\frac{\pi \beta_{i}}{a_{i}}}{1-\lambda \kappa_{1}^{2} \sigma_{\eta}^{2} \beta_{i}^{2}}$. We can calculate that

$$
\frac{\partial}{\partial \beta_{i}}\left(\frac{\beta_{i}^{2}\left(2-\frac{\pi \beta_{i}}{a_{i}}\right)}{1-\lambda \kappa_{1}^{2} \sigma_{\eta}^{2} \beta_{i}^{2}}\right)=\frac{\beta_{i}\left(4-\frac{3 \pi}{a_{i}} \beta_{i}+\frac{\pi}{a_{i}} \lambda \kappa_{1}^{2} \sigma_{\eta}^{2} \beta_{i}^{3}\right)}{\left(1-\lambda \kappa_{1}^{2} \sigma_{\eta}^{2} \beta_{i}^{2}\right)^{2}}
$$

Since $\beta_{i \gamma}<\sqrt{\frac{1}{\lambda \kappa_{1}^{2} \sigma_{\eta}^{2}}}, \frac{\partial}{\partial \beta_{i}}\left(4-\frac{3 \pi}{a_{i}} \beta_{i}+\frac{\pi}{a_{i}} \lambda \kappa_{1}^{2} \sigma_{\eta}^{2} \beta_{i}^{3}\right)=-\frac{3 \pi}{a_{i}}\left(1-\lambda \kappa_{1}^{2} \sigma_{\eta}^{2} \beta_{i}^{2}\right)<0$ for any $\beta_{i}$ between $\beta_{i \gamma}$ and $\sqrt{\frac{1}{\lambda \kappa_{1}^{2} \sigma_{\eta}^{2}}}$. Note that $\beta_{i 0}=\frac{2}{\frac{\pi}{a_{i}}+\sqrt{\left(\frac{\pi}{a_{i}}\right)^{2}-4 \lambda \kappa_{1}^{2} \sigma_{\eta}^{2}}}$ implies that $\frac{\pi}{a_{i}} \geq 2 \sqrt{\lambda \kappa_{1}^{2} \sigma_{\eta}^{2}}$, and thus, $\beta_{i 0} \leq \frac{2 a_{i}}{\pi} \leq$ $\sqrt{\frac{1}{\lambda \kappa_{1}^{2} \sigma_{\eta}^{2}}}$. It is easy to check that $\left.\left(4-\frac{3 \pi}{a_{i}} \beta_{i}+\frac{\pi}{a_{i}} \lambda \kappa_{1}^{2} \sigma_{\eta}^{2} \beta_{i}^{3}\right)\right|_{\beta_{i}=\beta_{i 0}}>0$, and $\beta_{i \gamma}<\beta_{i 0} \leq \sqrt{\frac{1}{\lambda \kappa_{1}^{2} \sigma_{\eta}^{2}}}$, so $\left.\left(4-\frac{3 \pi}{a_{i}} \beta_{i}+\frac{\pi}{a_{i}} \lambda \kappa_{1}^{2} \sigma_{\eta}^{2} \beta_{i}^{3}\right)\right|_{\beta_{i}=\beta_{i \gamma}}>0$. Since the risk premium $\frac{1}{2} \lambda \kappa_{1}^{2} a_{i}^{2} \sigma_{\eta}^{2} \beta_{i}^{2} \frac{2-\frac{\pi \beta_{i}}{a_{i}}}{1-\lambda \kappa_{1}^{2} \sigma_{\eta}^{2} \beta_{i}^{2}}$ is affected by $\sigma_{m}^{2}$ only through its effect on $\beta_{i}$, we have

$$
\frac{\partial}{\partial \sigma_{m}^{2}}\left[\frac{1}{2} \lambda \kappa_{1}^{2} a_{i}^{2} \sigma_{\eta}^{2} \beta_{i}^{2} \frac{2-\frac{\pi \beta_{i}}{a_{i}}}{1-\lambda \kappa_{1}^{2} \sigma_{\eta}^{2} \beta_{i}^{2}}\right]=\frac{\partial}{\partial \beta_{i}}\left[\frac{1}{2} \lambda \kappa_{1}^{2} a_{i}^{2} \sigma_{\eta}^{2} \beta_{i}^{2} \frac{2-\frac{\pi \beta_{i}}{a_{i}}}{1-\lambda \kappa_{1}^{2} \sigma_{\eta}^{2} \beta_{i}^{2}}\right] \frac{\partial \beta_{i}}{\partial \sigma_{m}^{2}}<0 \text { at } \beta_{i}=\beta_{i \gamma} .
$$

So the risk premium is decreasing in $\sigma_{m}^{2}$. Note that when $\sigma_{m}^{2}=0$, we will have the same risk premium in both the no-pay-for-luck equilibrium and the pay-for-luck equilibrium. Therefore, the shareholders' payoff is better in the pay-for-luck equilibrium than that in the no-pay-for-luck equilibrium as long as $\sigma_{m}^{2}>0$.

Proof of Proposition 3: When $\kappa_{1}=0$, the shareholders' objective is

$$
\min _{\beta_{i}, \gamma_{i}} \frac{1}{2} \lambda_{i}\left[\left(\gamma_{i} \kappa_{2}-h_{s} M\right)^{2} \sigma_{m}^{2}+\beta_{i}^{2} \kappa_{2}^{2} \sigma_{\eta}^{2}\right]
$$

subject to $a_{i}=\beta_{i} \pi$. Obviously, $\gamma_{i}$ must be set such that $\gamma_{i} \kappa_{2}-h_{s} M=0$. But since in equilibrium, $\gamma_{i}=\gamma$ and $M=\gamma \kappa_{2}$, this is impossible to get $\gamma_{i} \kappa_{2}=h_{s} M$ when $h_{s} \neq 1$.

Proof of Proposition 4: We have shown that if $h_{s}>1$, there are two equilibria. In one equilibrium, $\gamma_{i}=0$. In this case, $a_{i}=\frac{\beta_{i} \pi+\lambda \beta_{i}^{2} \kappa_{1}^{2} \bar{a} \sigma_{m}^{2}}{1+\lambda \beta_{i}^{2} \kappa_{1}^{2}\left(\sigma_{m}^{2}+\sigma_{\eta}^{2}\right)}$ with $\bar{a}=a_{i}$. Thus, the problem can be simplified to $a_{i}=\frac{\pi \beta_{i}}{1+\lambda \kappa_{1}^{2} \sigma_{\eta}^{2} \beta_{i}^{2}}$, and the shareholders' objective is to maximize

$$
\pi a_{i}-\frac{1}{2} \lambda \kappa_{1}^{2} a_{i}^{2} \sigma_{\eta}^{2} \beta_{i}^{2}-\frac{1}{2} a_{i}^{2}
$$


Plugging $\beta_{i}=\frac{\frac{\pi}{a_{i}}-\sqrt{\left(\frac{\pi}{a_{i}}\right)^{2}-4 \lambda \kappa_{1}^{2} \sigma_{\eta}^{2}}}{2 \lambda \kappa_{1}^{2} \sigma_{\eta}^{2}}$ into the above objective function, it is easy to derive that the optimal target effort is $a^{*}=\frac{\pi}{\sqrt{1+4 \lambda \kappa_{1}^{2} \sigma_{\eta}^{2}}}$.

In the other equilibrium, $\gamma_{i}>0$. Recall that the risk premium in this case is $\frac{1}{2} \lambda \kappa_{1}^{2} a_{i}^{2} \sigma_{\eta}^{2} \beta_{i \gamma}^{2}\left[\frac{\lambda^{2} \kappa_{1}^{4} \sigma_{m}^{2} \sigma_{\eta}^{2} \beta_{i \gamma}^{4}}{\left(1-\lambda \beta_{i \gamma}^{2} \kappa_{1}^{2} \sigma_{\eta}^{2}\right)^{2}}+1\right]$, where $\beta_{i \gamma}$ is the minimum (positive) solution to (6). We use $R P\left(a_{i}, \beta_{i \gamma}\left(a_{i}\right)\right)$ to denote this risk premium. Then the optimal target effort is to maximize $\pi a_{i}-R P\left(a_{i}, \beta_{i \gamma}\left(a_{i}\right)\right)-\frac{1}{2} a_{i}^{2}$. Taking the FOC w.r.t. $a_{i}$ yields that

$$
\pi-\lambda \kappa_{1}^{2} a_{i} \sigma_{\eta}^{2} \beta_{i \gamma}^{2}\left[\frac{\lambda^{2} \kappa_{1}^{4} \sigma_{m}^{2} \sigma_{\eta}^{2} \beta_{i \gamma}^{4}}{\left(1-\lambda \beta_{i \gamma}^{2} \kappa_{1}^{2} \sigma_{\eta}^{2}\right)^{2}}+1\right]-\frac{\partial R P}{\partial \beta_{i \gamma}} \frac{\partial \beta_{i \gamma}}{\partial a_{i}}-a_{i}=0
$$

By (6), $\frac{\lambda^{2} \kappa_{1}^{4} \sigma_{m}^{2} \sigma_{\eta}^{2} \beta_{i \gamma}^{4}}{\left(1-\lambda \beta_{i \gamma}^{2} \kappa_{1}^{2} \sigma_{\eta}^{2}\right)^{2}}+1=\frac{2-\frac{\pi \beta_{i \gamma}}{a_{i}}}{1-\lambda \kappa_{1}^{2} \sigma_{\eta}^{2} \beta_{i \gamma}^{2}}$. Together with (8), we can rewrite (9) as

$$
\pi-\lambda \kappa_{1}^{2} a_{i} \sigma_{\eta}^{2} \beta_{i \gamma}^{2} \frac{2-\frac{\pi \beta_{i \gamma}}{a_{i}}}{1-\lambda \kappa_{1}^{2} \sigma_{\eta}^{2} \beta_{i \gamma}^{2}}-\frac{\partial}{\partial \beta_{i \gamma}}\left(\frac{1}{2} \lambda \kappa_{1}^{2} a_{i}^{2} \sigma_{\eta}^{2} \beta_{i \gamma}^{2} \frac{2-\frac{\pi \beta_{i \gamma}}{a_{i}}}{1-\lambda \kappa_{1}^{2} \sigma_{\eta}^{2} \beta_{i \gamma}^{2}}\right) \frac{\partial \beta_{i \gamma}}{\partial a_{i}}-a_{i}=0 .
$$

Let $G\left(a_{i}, \beta_{i \gamma}\right)$ denote the left-hand side of the above equation. We first rewrite (6) as follows:

$$
\lambda \kappa_{1}^{2} \sigma_{\eta}^{2} \beta_{i}^{2}-\frac{\pi}{a_{i}} \beta_{i}+1-\frac{\lambda^{2} \kappa_{1}^{4} \sigma_{m}^{2} \sigma_{\eta}^{2} \beta_{i}^{4}}{1-\lambda \kappa_{1}^{2} \sigma_{\eta}^{2} \beta_{i}^{2}}=0
$$

$\beta_{i \gamma}$ is the minimum (positive) solution to (10). Let $J\left(\beta_{i}, a_{i}, \sigma_{m}^{2}\right)$ denote the left-hand side of (10). By the Implicit Function Theorem, $\frac{\partial \beta_{i \gamma}}{\partial a_{i}}=-\frac{\partial J}{\partial a_{i}} /\left.\frac{\partial J}{\partial \beta_{i}}\right|_{\beta_{i}=\beta_{i \gamma}}$. We can calculate that $\frac{\partial J}{\partial a_{i}}=\frac{\pi \beta_{i}}{a_{i}^{2}}$, and $\frac{\partial J}{\partial \beta_{i}}=2 \lambda \kappa_{1}^{2} \sigma_{\eta}^{2} \beta_{i}-\frac{\pi}{a_{i}}-\frac{2 \lambda^{2} \kappa_{1}^{4} \sigma_{m}^{2} \sigma_{\eta}^{2} \beta_{i}^{3}\left(2-\lambda \kappa_{1}^{2} \sigma_{\eta}^{2} \beta_{i}^{2}\right)}{\left(1-\lambda \kappa_{1}^{2} \sigma_{\eta}^{2} \beta_{i}^{2}\right)^{2}}=2 \lambda \kappa_{1}^{2} \sigma_{\eta}^{2} \beta_{i}-\frac{\pi}{a_{i}}-\frac{2\left(\lambda \kappa_{1}^{2} \sigma_{\eta}^{2} \beta_{i}^{2}-\frac{\pi}{a_{i}} \beta_{i}+1\right)\left(2-\lambda \kappa_{1}^{2} \sigma_{\eta}^{2} \beta_{i}^{2}\right)}{\beta_{i}\left(1-\lambda \kappa_{1}^{2} \sigma_{\eta}^{2} \beta_{i}^{2}\right)}=$ $-\frac{4-\frac{3 \pi}{a_{i}} \beta_{i}+\frac{\pi}{a_{i}} \lambda \kappa_{1}^{2} \sigma_{\eta}^{2} \beta_{i}^{3}}{\beta_{i}\left(1-\lambda \kappa_{1}^{2} \sigma_{\eta}^{2} \beta_{i}^{2}\right)}$. Together with (8), we can obtain that

$$
\frac{\partial}{\partial \beta_{i \gamma}}\left(\frac{1}{2} \lambda \kappa_{1}^{2} a_{i}^{2} \sigma_{\eta}^{2} \beta_{i \gamma}^{2} \frac{2-\frac{\pi \beta_{i \gamma}}{a_{i}}}{1-\lambda \kappa_{1}^{2} \sigma_{\eta}^{2} \beta_{i \gamma}^{2}}\right) \frac{\partial \beta_{i \gamma}}{\partial a_{i}}=\frac{\lambda \kappa_{1}^{2} \pi \sigma_{\eta}^{2} \beta_{i \gamma}^{3}}{2\left(1-\lambda \kappa_{1}^{2} \sigma_{\eta}^{2} \beta_{i \gamma}^{2}\right)} .
$$

Thus,

$$
G\left(a_{i}, \beta_{i \gamma}\right)=\pi-\lambda \kappa_{1}^{2} a_{i} \sigma_{\eta}^{2} \beta_{i \gamma}^{2} \frac{2-\frac{\pi \beta_{i \gamma}}{a_{i}}}{1-\lambda \kappa_{1}^{2} \sigma_{\eta}^{2} \beta_{i \gamma}^{2}}-\frac{\lambda \kappa_{1}^{2} \pi \sigma_{\eta}^{2} \beta_{i \gamma}^{3}}{2\left(1-\lambda \kappa_{1}^{2} \sigma_{\eta}^{2} \beta_{i \gamma}^{2}\right)}-a_{i} .
$$

Note that $\frac{\partial G}{\partial a_{i}}<0, \frac{\partial G}{\partial \beta_{i \gamma}}<0$, and $\frac{\partial \beta_{i \gamma}}{\partial a_{i}}>0$, so $\frac{d G}{d a_{i}}=\frac{\partial G}{\partial a_{i}}+\frac{\partial G}{\partial \beta_{i \gamma}} \frac{\partial \beta_{i \gamma}}{\partial a_{i}}<0$. Therefore, there is a unique solution to (9), i.e., the optimal target effort is unique. Moreover, by the Implicit Function Theorem, $\frac{\partial a_{i}}{\partial \sigma_{m}^{2}}$ has the same sign as $\frac{\partial G}{\partial \sigma_{m}^{2}}$, which equals $\frac{\partial G}{\partial \beta_{i \gamma}} \frac{\partial \beta_{i \gamma}}{\partial \sigma_{m}^{2}}>0$. So the optimal target effort 
increases in $\sigma_{m}^{2}$. It is easy to check that when $\sigma_{m}^{2}=0$, the two equilibria have the same optimal target effort. So the optimal target effort in the pay-for-luck equilibrium is higher than that in the no-pay-for-luck equilibrium as long as $\sigma_{m}^{2}>0$.

To derive the negative relation between the optimal $a_{i}$ and $\sigma_{\eta}$, we need to show that, fixing $a_{i}$, $G$ is decreasing in $\sigma_{\eta}$. First, we define $y=\sigma_{\eta} \beta_{i \gamma}$. By (10), $y$ is the minimum (positive) solution to $\lambda \kappa_{1}^{2} y^{2}-\frac{\pi}{a_{i} \sigma_{\eta}} y+1-\frac{\lambda^{2} \kappa_{1}^{4} \sigma_{m}^{2} y^{4}}{\sigma_{\eta}^{2}\left(1-\lambda \kappa_{1}^{2} \sigma_{\eta}^{2} \beta_{i}^{2}\right)}=0$. Then by the Implicit Function Theorem, it is easy to derive that $\frac{\partial y}{\partial \sigma_{\eta}}>0$. Second, we show that $X=\frac{\sigma_{\eta}^{2} \beta_{i \gamma}^{3}}{1-\lambda \kappa_{1}^{2} \sigma_{\eta}^{2} \beta_{i \gamma}^{2}}$ is increasing in $\sigma_{\eta}$. The proof is as follows: if $\beta_{i \gamma}$ increases in $\sigma_{\eta}$, then note that $\frac{\partial X}{\partial \beta_{i \gamma}}$ and $\frac{\partial X}{\partial \sigma_{\eta}}$ are both positive, so $\frac{d X}{d \sigma_{\eta}}>0$. If $\beta_{i \gamma}$ decreases in $\sigma_{\eta}$, then by (10), $X=\frac{1}{\lambda^{2} \kappa_{1}^{4} \sigma_{m}^{2}}\left[\lambda \kappa_{1}^{2} \sigma_{\eta}^{2} \beta_{i \gamma}-\frac{\pi}{a_{i}}+\frac{1}{\beta_{i \gamma}}\right]$. Since $\beta_{i \gamma}<\sqrt{\frac{1}{\lambda \kappa_{1}^{2} \sigma_{\eta}^{2}}}, \lambda \kappa_{1}^{2} \sigma_{\eta}^{2} \beta_{i \gamma}-\frac{\pi}{a_{i}}+\frac{1}{\beta_{i \gamma}}$ increases in $\sigma_{\eta}$ if $\beta_{i \gamma}$ decreases in $\sigma_{\eta}$. Thus, we prove that $X=\frac{\sigma_{\eta}^{2} \beta_{i \gamma}^{3}}{1-\lambda \kappa_{1}^{2} \sigma_{\eta}^{2} \beta_{i \gamma}^{2}}$ is increasing in $\sigma_{\eta}$. The left-hand side of (9) (i.e., $G$ ) can be rewritten as $\pi-\left[\lambda^{3} \kappa_{1}^{6} \sigma_{m}^{2} a_{i} X^{2}+\lambda \kappa_{1}^{2} a y^{2}\right]-\frac{\lambda \kappa_{1}^{2} \pi X}{2}-a_{i}$, which is obviously decreasing in $\sigma_{\eta}$ for fixing $a_{i}$. Thus, by the Implicit Function Theorem, the optimal $a_{i}$ decreases in $\sigma_{\eta}^{2}$.

Proof of Lemma 3: The CEO pay must be binding in the participation constraint, so we have

$$
\alpha_{i}+\beta_{i} \pi a_{i}-h_{l} W-\frac{1}{2} \lambda\left[\left(\beta_{i} \kappa_{1}\left(a_{i}-\bar{a}\right)+\gamma_{i}\left(\kappa_{1} \bar{a}+\kappa_{2}\right)-h_{s} M\right)^{2} \sigma_{m}^{2}+\beta_{i}^{2}\left(\kappa_{1} a_{i}+\kappa_{2}\right)^{2} \sigma_{\eta}^{2}\right]-\frac{1}{2} a_{i}^{2}=\bar{u},
$$

where $\bar{u}$ is the certainty-equivalent of the reservation utility. Note that $W=\alpha_{i}+\beta_{i} \pi \bar{a}$ and $a_{i}=\bar{a}$ in equilibrium; thus,

$$
E[w]=\alpha_{i}+\beta_{i} \pi \bar{a}=\frac{1}{1-h_{l}}(\text { risk premium }+ \text { cost of effort }+\bar{u}) .
$$

Proof of Proposition 5: As in the baseline model, we can calculate that the certaintyequivalent of the expected utility is

$$
\alpha_{i}+\beta_{i} \pi a_{i}-h_{l} W-\frac{1}{2} \lambda\left[\left(\beta_{i}\left(\kappa_{1}\left(a_{i}-\bar{a}\right)+\theta_{i}-\bar{\theta}\right)+\gamma_{i}\left(\kappa_{1} \bar{a}+\bar{\theta}\right)-h_{s} M\right)^{2} \sigma_{m}^{2}+\beta_{i}^{2} \kappa_{1}^{2} a_{i}^{2} \sigma_{\eta}^{2}\right]-\frac{1}{2} a_{i}^{2} .
$$

Since in equilibrium $\gamma_{i}=\gamma, \theta_{i}=\bar{\theta}, M=\gamma\left(\kappa_{1} \bar{a}+\bar{\theta}\right), a_{i}=\bar{a}$, and $h_{s}>1, \beta_{i}\left(\kappa_{1}\left(a_{i}-\bar{a}\right)+\theta_{i}-\bar{\theta}\right)+$ $\gamma_{i}\left(\kappa_{1} \bar{a}+\bar{\theta}\right)-h_{s} M<0$. Therefore, given $M$, the manager will choose $\theta_{i}$ as large as possible to catch up with his peers' exposure to the aggregate shock. So the manager will choose $\theta_{i}=\theta_{h}$ optimally.

Following the similar procedure as in the baseline model, we can show that $\kappa_{1}\left(a_{i}-\bar{a}\right)+\theta_{i}-$ $\bar{\theta}+\gamma_{i}\left(\kappa_{1} \bar{a}+\bar{\theta}\right)-h_{s} M=-\frac{\lambda \kappa_{1}^{3} \beta_{i}^{3} \sigma_{\eta}^{2} a_{i}}{1-\lambda \beta_{i}^{2} \kappa_{1}^{2} \sigma_{\eta}^{2}}$. Then it is easy to check that $\beta_{i}$ is the minimum (positive) 
solution to (6), and the optimal target effort is the solution to (9). Then using the same procedure as in the baseline model, we can show that as long as $\sigma_{m}^{2}>0$, the shareholders' payoff is better in the pay-for-luck equilibrium than in the no-pay-for-luck equilibrium, and the optimal target effort in the pay-for-luck equilibrium is higher than that in the no-pay-for-luck equilibrium.

Proof of Proposition 6, 7, and 8: Given that the relative concerns with respect to the economy can take the form: $\tilde{w}_{e}=h_{l} W_{e}+h_{s} M_{e} \tilde{m}$, the proofs of these three propositions are just similar to the proofs of Proposition 2, 4, and 5. Moreover, similar to the proof of Proposition 1, the threshold $\hat{h}$ goes to 0 as $\kappa_{1}$ approaches 0 .

Proof of Proposition 9: Since when the relative concerns are global, $h_{s} M_{e}=h_{s} \kappa_{2}$, the shareholders will set $\gamma=h_{s}$ to avoid paying the risk premium associated with luck shocks. Thus, $\gamma>0$ as long as $h_{s}>0$. When the manager is allowed to make the additional risk choice $\theta$, the manager's net exposure to the luck shocks is $\beta_{i}\left(\theta_{i}-\bar{\theta}\right)+\gamma_{i}\left(\kappa_{2}+\bar{\theta}\right)-h_{s}\left(\kappa_{2}+\bar{\theta}\right)$, which always equals to zero in equilibrium. Thus, it is easy to verify that any value in $\left[\theta_{l}, \theta_{h}\right]$ for $\theta$ can be an equilibrium.

\section{Proofs for Appendix C}

Proof of Proposition 12: It is easy to show that $\tilde{w}$ can be simplified to $\tilde{w}=h_{l} W+h_{s} \int_{0}^{1} f(k) d k M \tilde{m}$. Thus, the rest of the proof is similar to the proof of the baseline model.

Proof of Proposition 13: $I_{\left\{w_{k}>w\right\}}=I_{\left\{\eta_{k}>\eta\right\}}$ is a random variable that equals 1 or 0 with equal probability, and $I_{\left\{w_{k}>w\right\}}, k \in[0,1]$ are independent of each other. Then $\tilde{w}=h_{l} W+$ $h_{s} M \tilde{m} \int_{0}^{1} I_{\left\{\eta_{k}>\eta\right\}} d k+h_{s} \beta_{i} \kappa_{1} \bar{a} \int_{0}^{1} I_{\left\{\eta_{k}>\eta\right\}} \eta_{k} d k$. By the law of large numbers, $\int_{0}^{1} I_{\left\{\eta_{k}>\eta\right\}} d k$ converges to $E\left[I_{\left\{\eta_{k}>\eta\right\}}\right]=\frac{1}{2}$, and $\int_{0}^{1} I_{\left\{\eta_{k}>\eta\right\}} \eta_{k} d k$ converges to $E\left[I_{\left\{\eta_{k}>\eta\right\}} \eta_{k}\right]$, which is a constant. Therefore, $\tilde{w}$ can be rewritten as $\tilde{w}=h_{l} W+\frac{1}{2} h_{s} M \tilde{m}+$ constant. Then the rest of the proof is similar to the proof of the baseline model.

Proof of Proposition 14: We use $\alpha_{i}, \beta_{i}, \gamma_{i}, a_{i}$ to denote the compensation and effort choices for the firms and managers indexed by $i \in(0,1]$. For the leading manager, we use $\alpha_{0}, \beta_{0}, \gamma_{0}, a_{0}$ to denote the corresponding compensation and effort choices. Similar to the specification in the baseline model, let $\bar{a}$ be the average effort choice that equals $a_{i}$ in equilibrium, and let $\bar{a}_{0}$ be a weighted-average effort choice that equals $a_{0}$ in equilibrium. Then the compensation for the managers indexed by $i \in(0,1]$ has the form: $w_{i}=\alpha_{i}+\beta_{i}\left(\pi a_{i}+\kappa_{1} a_{i} \eta\right)+\left[\beta_{i} \kappa_{1}\left(a_{i}-\bar{a}\right)+\gamma_{i} \kappa_{1} \bar{a}\right] \tilde{m}$. The compensation for the leading manager is $w_{0}=\alpha_{0}+\beta_{0}\left(\pi a_{0}+\kappa_{1} a_{0} \eta_{0}\right)+\left[\beta_{0} \kappa_{1}\left(a_{0}-\bar{a}_{0}\right)+\gamma_{0} \kappa_{1} \bar{a}_{0}\right] \tilde{m}$. 
The certainty-equivalent utility for the managers indexed by $i \in(0,1]$ is

$$
\begin{aligned}
C E_{i} & =\alpha_{i}+\beta_{i} \pi a_{i}-h_{l} W-\frac{1}{2} \lambda\left(h_{0} \beta_{0} \kappa_{1} a_{0}\right)^{2} \sigma_{\eta}^{2} \\
& -\frac{1}{2} \lambda\left[\left(\beta_{i} \kappa_{1}\left(a_{i}-\bar{a}\right)+\gamma_{i} \kappa_{1} \bar{a}-h_{s} M-h_{0}\left(\beta_{0} \kappa_{1}\left(a_{0}-\bar{a}_{0}\right)+\gamma_{0} \kappa_{1} \bar{a}_{0}\right)\right)^{2} \sigma_{m}^{2}+\left(\beta_{i} \kappa_{1} a_{i}\right)^{2} \sigma_{\eta}^{2}\right]-\frac{1}{2} a_{i}^{2}
\end{aligned}
$$

Taking the first-order condition w.r.t $a_{i}$ yields that

$$
a_{i}=\frac{\beta_{i} \pi-\lambda \beta_{i} \kappa_{1} \sigma_{m}^{2}\left[-\beta_{i} \kappa_{1} \bar{a}+\gamma_{i} \kappa_{1} \bar{a}-h_{s} M-h_{0}\left(\beta_{0} \kappa_{1}\left(a_{0}-\bar{a}_{0}\right)+\gamma_{0} \kappa_{1} \bar{a}_{0}\right)\right]}{1+\lambda \beta_{i}^{2} \kappa_{1}^{2}\left(\sigma_{m}^{2}+\sigma_{\eta}^{2}\right)} .
$$

Note that the managers' effort is affected by the leading manager's compensation contract. In particular, $\frac{\partial a_{i}}{\partial \beta_{0}}=h_{0} \kappa_{1}\left(a_{0}-\bar{a}_{0}\right) X, \frac{\partial a_{i}}{\partial \gamma_{0}}=h_{0} \kappa_{1} \bar{a}_{0} X$, where $X=\frac{\lambda \beta_{i} \kappa_{1} \sigma_{m}^{2}}{1+\lambda \beta_{i}^{2} \kappa_{1}^{2}\left(\sigma_{m}^{2}+\sigma_{\eta}^{2}\right)}$.

Then following the same procedure as in the proof of the baseline model, we can show that $\beta_{i} \kappa_{1}\left(a_{i}-\bar{a}\right)+\gamma_{i} \kappa_{1} \bar{a}-h_{s} M-h_{0}\left(\beta_{0} \kappa_{1}\left(a_{0}-\bar{a}_{0}\right)+\gamma_{0} \kappa_{1} \bar{a}_{0}\right)=-\frac{\lambda \kappa_{1}^{3} \beta_{i}^{3} \sigma_{\eta}^{2} a_{i}}{1-\lambda \beta_{i}^{2} \kappa_{1}^{2} \sigma_{\eta}^{2}}$, and $\beta_{i}$ is the minimum positive solution to $(6)$.

The solution for the leading manager is complicated because his compensation contract will affect other managers' effort choices. The certainty-equivalent utility for the leading manager is

$$
\begin{aligned}
C E_{0} & =\alpha_{0}+\beta_{0} \pi a_{0}-h_{l}\left(\alpha_{i}+\beta_{i} \kappa_{1} a_{i}\right) \\
& -\frac{1}{2} \lambda\left[\left(\beta_{0} \kappa_{1}\left(a_{0}-\bar{a}_{0}\right)+\gamma_{0} \kappa_{1} \bar{a}_{0}-h_{s}\left(\beta_{i} \kappa_{1}\left(a_{i}-\bar{a}\right)+\gamma_{i} \kappa_{1} \bar{a}\right)\right)^{2} \sigma_{m}^{2}+\beta_{0}^{2} \kappa_{1}^{2} a_{0}^{2} \sigma_{\eta}^{2}\right]-\frac{1}{2} a_{0}^{2} .
\end{aligned}
$$

Taking first-order condition w.r.t $a_{0}$ yields that

$$
a_{0}=\frac{\beta_{0} \pi-\lambda \sigma_{m}^{2} \beta_{0} \kappa_{1}\left(-\beta_{0} \kappa_{1} \bar{a}_{0}+\gamma_{0} \kappa_{1} \bar{a}_{0}-h_{s}\left(\beta_{i} \kappa_{1}(a-\bar{a})+\gamma_{i} \kappa_{1} \bar{a}\right)\right)}{1+\lambda \beta_{0}^{2} \kappa_{1}^{2}\left(\sigma_{m}^{2}+\sigma_{\eta}^{2}\right)} .
$$

Following the same procedure as in the proof of the baseline model, we can show that

$$
\gamma_{0} \kappa_{1} \bar{a}_{0}-h_{s} \gamma_{i} \kappa_{1} \bar{a}=-\frac{\lambda \kappa_{1}^{3} \beta_{0}^{3} \sigma_{\eta}^{2} a_{0}}{1-\lambda \beta_{0}^{2} \kappa_{1}^{2} \sigma_{\eta}^{2}}-\frac{h_{l} \beta_{i} \kappa_{1} h_{0} X}{\lambda \sigma_{m}^{2}\left(1-h_{s} \beta_{i} \kappa_{1} h_{0} X\right)} .
$$

$\beta_{0}$ is a solution to $\lambda \kappa_{1}^{2} \sigma_{\eta}^{2} a_{0} \beta_{0}^{2}-\pi \beta_{0}+a_{0}-\lambda \kappa_{1} \sigma_{m}^{2} \beta_{0}\left(\frac{\lambda \kappa_{1}^{3} \sigma_{\eta}^{2} a_{0} \beta_{0}^{3}}{1-\lambda \beta_{0}^{2} \kappa_{1}^{2} \sigma_{\eta}^{2}}+\frac{h_{l} \beta_{i} \kappa_{1} h_{0} X}{\lambda \sigma_{m}^{2}\left(1-h_{s} \beta_{i} \kappa_{1} h_{0} X\right)}\right)=0$. Recall that for other managers, we have that $\gamma_{i} \kappa_{1} \bar{a}-h_{s} \gamma_{i} \kappa_{1} \bar{a}-h_{0} \gamma_{0} \kappa_{1} \bar{a}_{0}=-\frac{\lambda \kappa_{1}^{3} \beta_{i}^{3} \sigma_{\eta}^{2} a_{i}}{1-\lambda \beta_{i}^{2} \kappa_{1}^{2} \sigma_{\eta}^{2}}$.

If $h_{s} h_{0}<1$, it is easy to check that $1-h_{s} \beta_{i} \kappa_{1} h_{0} X>0$. Denote $U=\frac{\lambda \kappa_{1}^{3} \beta_{0}^{3} \sigma_{\eta}^{2} a_{0}}{1-\lambda \beta_{0}^{2} \kappa_{1}^{2} \sigma_{\eta}^{2}}+\frac{h_{l} \beta_{i} \kappa_{1} h_{0} X}{\lambda \sigma_{m}^{2}\left(1-h_{s} \beta_{i} \kappa_{1} h_{0} X\right)}>$ 0 , and $V=\frac{\lambda \kappa_{1}^{3} \beta_{i}^{3} \sigma_{\eta}^{2} a_{i}}{1-\lambda \beta_{i}^{2} \kappa_{1}^{2} \sigma_{\eta}^{2}}>0$. If $h_{l}=0$, then following the same procedure as in the proof of the baseline model, we can check that the optimal $a_{0}$ and $\beta_{0}$ equal the optimal $a$ and $\beta_{i}$, respectively. 
Thus, $U=V$ when $h_{l}=0$. Moreover, we can also show that if $h_{s}<\frac{1}{1+h_{0}}$, there is only one equilibrium with no pay-for-luck; if $h_{s}>\frac{1}{1+h_{0}}$, there exist two equilibria. In one equilibrium, $\gamma_{0}=\gamma_{i}=0$; in the other equilibrium, $\gamma_{0}, \gamma_{i}>0$. The shareholders' payoff in the pay-for-luck equilibrium is greater than that in the no-pay-for-luck equilibrium. By the continuity, when $h_{l}$ is small enough, the results still hold. 